\title{
Oil Price Pass-through into Core Inflation
}

\author{
Cristina Conflitti a ${ }^{\text {and Matteo Luciani }}{ }^{\text {b }}$
}

\begin{abstract}
We estimate the oil price pass-through into consumer prices both in the U.S. and in the euro area. In particular, we disentangle the specific effect that an oil price change might have on each disaggregate price, from the effect on all prices that an oil price change might have since it affects the whole economy. To do so, we first estimate a Dynamic Factor Model on a panel of disaggregate price indicators, and then we use VAR techniques to estimate the pass-through. Our results show that the oil price passes through core inflation only via its effect on the whole economy. This pass-through is estimated to be small, but statistically different from zero and long lasting.
\end{abstract}

Keywords: Core inflation, Oil price, Dynamic factor model, Pass-through, Disaggregate consumer prices

https://doi.org/10.5547/01956574.40.6.ccon

\section{INTRODUCTION}

Quantifying the magnitude and establishing the timing of the pass-through of oil price changes to consumer prices is crucial, particularly so because oil prices tend to undergo wide fluctuations. Consider the plunge of oil prices from July 2014 to February 2016, from about $\$ 100$ per barrel to $\$ 30$. What is the effect of such a large swing in oil prices on core inflation? And how long will this effect last? Different answers to this question have very different implications for inflation forecasting, and hence for the stance of monetary policy.

Oil price fluctuations affect consumer inflation through both its energy component and the non-energy components. However, while there is clear evidence that the pass-through from oil prices to energy prices is relatively fast and complete (Burdette and Zyren, 2003; Meyler, 2009), as well as symmetric (Baumeister and Kilian, 2016), it is unclear to what degree changes in oil prices pass-through into non-energy prices (Kilian and Lewis, 2011; Kilian, 2014).

In theory, an increase in oil prices might have an inflationary effect in at least three ways. First, because energy prices represent a considerable portion of production costs for a few sectors. Second, because it might lead to higher inflation expectations. Third, because it might lead workers to demand a higher wage to compensate for the increase in energy prices (Bruno and Sachs, 1985; Blanchard and Gali, 2009). By contrast, an increase in oil prices might have a deflationary effect in the same fashion as an adverse demand shock because higher energy prices tend to reduce net-dis-

a_Banca d'Italia. E-mail: cristina.conflitti@bancaditalia.it.

b Corresponding author. Board of Governors of the Federal Reserve System. Send correspondence to Board of Governors of the Federal Reserve System, 20th Street and Constitution Avenue N.W., Washington, DC 20551, USA. 20551. E-mail: matteo.luciani@frb.gov.

The Energy Journal, Vol. 40, No. 6. This is an open access article under the terms of the Creative Commons Attribution License (CC-BY), which permits use, distribution and reproduction in any medium, provided the original work is properly cited. All rights reserved. 
posable income, and thus consumption (Edelstein and Kilian, 2009; Baumeister and Kilian, 2016; Baumeister et al., 2018) and investments (Edelstein and Kilian, 2007).

Empirically, despite extensive evidence that changes in the oil price contribute to macroeconomic fluctuations (see Hooker, 1996; Barsky and Kilian, 2002; Kilian, 2008b, 2009a,b; Kilian and Vigfusson, 2011, 2017, among others), various authors have shown that the pass-through of oil price changes to core prices has declined since the mid-eighties (see Hooker, 2002; Chen, 2009; Clark and Terry, 2010, among others) up to the point that it is very limited if not zero (for example Cavallo, 2008; Clark and Terry, 2010).

In this paper we use a different methodological approach to estimate the oil price passthrough into core consumer prices. Our starting point is that fluctuations in disaggregate prices are the result of both macroeconomic shocks, as well as idiosyncratic shocks or measurement error. Hence, in order to estimate correctly the pass-through of a change in the oil price, we have first to disentangle price fluctuations due to macroeconomic shocks, from price fluctuations due to idiosyncratic shocks and measurement error. This is particularly true, given that idiosyncratic shocks can have a non-negligible effect on core prices - for example, the plunge of the wireless telephone services index that occurred in March 2017, which shaved of about a tenth of a percentage point to core inflation.

Our empirical strategy consists in using a restricted version of the structural dynamic factor model (Forni et al., 2009) very similar to a FAVAR model (Bernanke et al., 2005). In practice, we first estimate a dynamic factor model on a panel of disaggregate prices, thus allowing us to disentangle common changes in disaggregate prices due to macroeconomic fluctuations from idiosyncratic changes due to sector specific characteristics. And then, we use VAR techniques to estimate the oil price pass-through via the common component, as well as via the idiosyncratic component. Both these pass-through are likely to be important. Indeed, given that they contribute to macroeconomic fluctuations, changes in the oil price might pass-through into core inflation via the common/macroeconomic component. At the same time, changes in the oil price might have a direct effect on some disaggregate price - those whose production is particularly energy intensive - and therefore they might also pass-through into core inflation via some idiosyncratic component.

Our empirical analysis is carried out on a panel of U.S. personal consumption expenditure (PCE) disaggregate price indexes from 1984 to 2016. We show that an oil price change passes-through core PCE prices only via its effect on the whole economy, while the direct effect via the cost channel is null. Moreover, the subsample analysis confirms the result in the literature whereby the oil price pass-through into core inflation has decreased over time. However, in contrast with part of this literature (for example Clark and Terry, 2010) we always find a statistically significant passthrough. Finally, we estimate the oil price pass-through on a panel of euro area harmonized index of consumer prices (HICP) at a disaggregate level. This estimate yields a euro area pass-through similar to that of the U.S..

Our results are different from those available in the literature, because it turns out that common and idiosyncratic dynamics in disaggregate prices have different statistical properties: common dynamics are slow moving, idiosyncratic dynamics fast moving and volatile. Therefore, disentangling these two components, which is the novel feature of this paper, is crucial, as in this way the noisy idiosyncratic component does not affect estimation results.

Other papers have used dynamic factor models to study the effects of oil price fluctuations on the economy, but none have focused on the pass-through into consumer prices. For example, Aastveit (2014), Aastveit et al. (2015), Juvenal and Petrella (2015), and Stock and Watson (2016) study the effects of different structural oil price shocks on the economy, while An et al. (2014) study 
whether oil price shocks have asymmetric effects on the economy. Moreover, other papers have used dynamic factor models to analyze disaggregate prices (Cristadoro et al., 2005; Altissimo et al., 2009; Boivin et al., 2009; Reis and Watson, 2010; De Graeve and Walentin, 2015, among others), but none have used these models to study the oil price pass-through. Finally, Gao et al. (2014) study the effect of oil price shocks on a number of disaggregate U.S. consumer prices using VAR techniques; they find a significant effect only on the price of energy-intensive goods but do not distinguish between macroeconomic and idiosyncratic effects.

The rest of the paper proceeds as follows. Section 2 presents the methodology. Section 3 presents the empirical analysis on the U.S., namely: Section 3.1 describes the data used, and Section 3.2 discusses common and idiosyncratic dynamics in U.S. PCE prices. Then, Section 3.3 presents estimates of the oil price pass-through, and Section 3.4 presents subsample analysis. Finally, Section 4 presents the empirical analysis on the euro area, and Section 5 briefly summarizes the results.

\section{THE ECONOMETRIC FRAMEWORK}

The goal of this paper is to quantify the effect of oil price changes on core price inflation. More precisely, we aim to disentangle the specific (idiosyncratic) effect that an oil price change might have on each disaggregate price, from its macroeconomic (common) effect that an oil price change has on all prices. To do so, we first estimate a dynamic factor model on a panel of price indicators to separate common from idiosyncratic price changes, and then use VAR techniques to estimate the pass-through.

Factor models are based on the idea that fluctuations in disaggregate prices are due to a few common (macroeconomic) shocks $\left(\mathbf{u}_{t}\right)$ that affect all prices, and to several idiosyncratic shocks $\left(\mathbf{e}_{t}\right)$, resulting from sector-specific dynamics or from sampling error, which influence one or a few of them. Accordingly, each price component in the dataset can be decomposed into a common part $\chi_{i t}$, which is a linear combination of a small number $r$ of common factors $\mathbf{f}_{t}$ that are driven by the common shocks, and an idiosyncratic part $\xi_{i t}$ that is driven by idiosyncratic shocks. Let $\pi_{i t}=1200 \times \log \left(\frac{P_{i t}}{P_{i t-1}}\right)$ be the annualized month-on-month log-change in the $i$-th price component at time $t$, where $i=1, \ldots ., n$ and $t=1, \ldots ., T$, we then have

$$
\pi_{i t}=\chi_{i t}+\xi_{i t}=\lambda_{i}^{\prime} \mathbf{f}_{t}+\xi_{i t}
$$

where $\lambda_{i}$ is a $r \times 1$ vector containing the factor loadings of the $i$-th variable, and $\chi_{i t}=\lambda_{i}^{\prime} \mathbf{f}_{t}$. Model (1) is the approximate dynamic factor model proposed by Stock and Watson (2002a,b), which is a particular case of the generalized dynamic factor model studied by Forni et al. (2000) and Forni and Lippi (2001).

It is well documented that changes in the oil price contribute to macroeconomic fluctuations (see Hooker, 1996; Barsky and Kilian, 2002; Kilian, 2008b, 2009b, among others), thus they are likely to have a macroeconomic effect on all prices. To incorporate this feature in our model, we assume that the common factors and the oil price evolve over time according to a VAR model. Let $y_{t}=\Delta \log \left(\frac{\text { oil }_{t}}{\text { price }_{t}}\right)$ be the monthly real oil price growth rate, then we have

$$
\mathbf{A}(L)\left(\begin{array}{l}
y_{t} \\
\mathbf{f}_{t}
\end{array}\right)=\left(\begin{array}{l}
v_{t} \\
\mathbf{u}_{t}
\end{array}\right)
$$

where $v_{t}$ is "the oil price shock". 
At the same time, given that sectors are more or less energy intensive so that energy costs represent a larger or smaller share of total costs, a change in the oil price might have a direct effect to those disaggregate prices which production is particularly energy intensive. This points at the possibility that a change in the oil price passes-through into core inflation also via some idiosyncratic component, and therefore we allow for the possibility that the oil price and each idiosyncratic component evolve over time according to a bivariate VAR:

$$
\mathbf{B}_{i}(L)\left(\begin{array}{l}
y_{t} \\
\xi_{i t}
\end{array}\right)=\left(\begin{array}{l}
v_{t} \\
e_{i t}
\end{array}\right)
$$

Under the assumption that all the components of $\pi_{t}=\left(\begin{array}{llll}\pi_{1 t} & \pi_{2 t} & \ldots & \pi_{n t}\end{array}\right)^{\prime}$ are stationary, the common factors, the factor loadings, and the idiosyncratic components can be estimated by principal components (Stock and Watson, 2002a; Bai, 2003). Once the factors and the idiosyncratic components are estimated, the VAR in (2) and the $n$ VARs in (3) can be estimated by OLS simply by replacing $\mathbf{f}_{t}$ and $\xi_{i t}$ with their principal components estimates, with the estimated parameters converging at the standard rate $\min (\sqrt{n}, \sqrt{T})$ (Forni et al., 2009).

Once $\mathbf{A}(L)$ and $\mathbf{B}_{i}(L)$ are estimated, by defining $\mathbf{C}(L)=\mathbf{A}(L)^{-1}$ and $\mathbf{D}_{i}(L)=\mathbf{B}_{i}(L)^{-1}$, and by substituting (2) and (3) in (1) we get

$$
\begin{aligned}
\pi_{i t} & =\left(\lambda_{i} \mathbf{c}_{21}(L)+d_{i 21}(L)\right) v_{t}+\lambda_{i} \mathbf{c}_{22}(L) \mathbf{u}_{t}+\left(1+d_{i 22}(L)\right) e_{i t} \\
& =\psi_{i}^{\chi}(L) v_{t}+\psi_{i}^{\xi}(L) v_{t}+\phi_{i}(L) \mathbf{u}_{t}+\theta_{i}(L) e_{i t}
\end{aligned}
$$

where $\psi_{i}^{\chi}(L)$ and $\psi_{i}^{\xi}(L)$ measure, respectively, the common and the idiosyncratic pass-through of an unexpected and unpredictable change in the real oil price to the inflation rate of price $i$.

Having computed the oil price pass-through into each disaggregate price, we can construct the pass-through into core price inflation as:

$$
\psi_{c}(L)=\sum_{i \in \text { core }} w_{i} \psi_{i}^{\chi}(L)+\sum_{i \in \text { core }} w_{i} \psi_{i}^{\xi}(L)=\psi_{c}^{\chi}(L)+\psi_{c}^{\xi}(L)
$$

where $w_{i}$ is the PCE weight for item $i$.

Before moving to the empirical analysis, six methodological remarks are in order:

(I) Our model is very similar to a standard FAVAR model (Bernanke et al., 2005), which in its turn is a restricted version of the structural dynamic factor model first introduced by Giannone et al. (2005), Stock and Watson (2005), and Forni et al. (2009). In a FAVAR model the oil price is treated as an observed factor, which means that the oil price is part of the common space only, while not having any effects on the idiosyncratic component. In formulas, equation (1) is replaced by $\pi_{i t}=\lambda_{i}^{\prime} \mathbf{f}_{t}+\gamma_{i} y_{t}+\xi_{i t}$, while (2) stays the same and the idiosyncratic component is not modelled. As a robustness check, in Appendix 1 we show the estimated pass-through when a FAVAR model is used.

(II) We have to clarify that while we estimate the VAR (3) for all core prices in our dataset, we expect that a relationship between the real oil price and the idiosyncratic component of item $i$ exists only for very few items. This is the case because a change in the oil price is likely to have a direct effect only to those disaggregate prices which production is particularly energy intensive. The results in Section 3.3 and 4.3 corroborates this assumption as the oil price pass-through into the idiosyncratic component is statistically different from zero only for very few core prices. Of course, had 
we found that this pass-through was statistically significant for many prices, than this would have violated some of the assumption of the approximate dynamic factor model in (1), and would have pointed at the existence of additional factors.

(III) As we explained above, we are working under the assumption that all the components of $\boldsymbol{\pi}_{t}$ are stationary. How sensitive are our results to this assumption? The answer boils down on whether the idiosyncratic components are stationary or not. Indeed, if the idiosyncratic components are stationary, the common factors, the factor loadings, and the idiosyncratic components can still be estimated by principal components even if the components of $\boldsymbol{\pi}_{t}$ are non-stationary (Bai, 2004). Conversely, if the idiosyncratic components are non-stationary, then principal components should be run on $\Delta \pi_{t}$ (Bai and Ng, 2004; Barigozzi et al., 2016). The question then is how credible is that the idiosyncratic components are stationary, or in other words how credible is that changes in disaggregate prices move around a common stochastic trend. Our answer is very credible, as this is what the data seems to point at (see also the discussion at the end of Section 3.2 and the results in Table 3).

(IV) By estimating a bivariate VAR between $\mathbf{f}_{t}$ ( or $\xi_{i t}$ ) extracted from a panel of log-differences of prices, and the log-difference of the real oil price, we are assuming that there is no cointegration between these two variables. We believe that this assumption is realistic since the oil price clearly appear not to be cointegrated with any of the core prices (results shown in the online appendix). The only price with which the oil price is cointegrated is gasoline price.

(V) In order to build confidence intervals for the estimated pass-through, we use a bootstrap algorithm. In detail, at each iteration $d$, we bootstrap the vector $\left(v_{t}^{d} \quad u_{t}^{d}\right)^{\prime}$ and we generate bootstrap common factors $\mathbf{f}_{t}^{d}$ and a bootstrap oil price $y_{t}^{d}$ using equation (2). Then, we estimate the parameters of equation (2), $\hat{\mathbf{A}}(L)^{d}$ and $\hat{\mathbf{C}}(L)^{d}$, and we estimate the $d$-th bootstrap oil price pass-through via the common component for item $i$ as $\hat{\psi}_{i}^{\chi}(L)^{d}=\hat{\lambda}_{i}^{\prime} \hat{\mathbf{c}}_{21}(L)^{d}$, and for core PCE as $\hat{\psi}_{c}^{\chi}(L)^{d}=\sum_{i \in c o r e} w_{i} \hat{\psi}_{i}^{\chi}(L)^{d}$. Repeating this procedure several times gives a bootstrap distribution of the oil price pass-through into core PCE prices via the common component. Having generated a bootstrap distribution for each lag $k$ we can compute the standard deviation $\sigma_{c k}^{\psi \prime}$ across the bootstrap draws, and then construct the $\alpha \%$ confidence bands as $\hat{\psi}_{c k}^{\chi} \pm z \sigma_{c k}^{\psi}$, where $z$ is the $\alpha$ percentile of a standard normal. A similar procedure is adopted for constructing confidence bands for the oil price pass-through via the idiosyncratic component.

(VI) As it is standard practice in factor analysis, before estimating equation (1) we have demeaned and standardized all PCE prices. As a result, (1) should read $\tilde{\pi}_{i t}=\lambda_{i}^{\prime} \mathbf{f}_{t}+\xi_{i t}$ where $\tilde{\pi}_{i t}=\frac{\pi_{i t}-\bar{\pi}_{i}}{\sigma_{\pi_{i}}}, \bar{\pi}_{i}$ and $\sigma_{\pi_{i}}$ are the sample mean and the standard deviation of $\pi_{i t}$, respectively. Then, when we estimate the pass-through in (4) we reattribute the standard deviation to each series.

\section{OIL PRICE PASS-THROUGH IN THE U.S.}

\subsection{Data}

The price data for the U.S. are monthly price indexes for personal consumption expenditures (PCE) by type of product. The data are taken from the NIPA Table 2.4.4U from the Bureau of Economic Analysis and downloaded from Haver. 
PCE price data are available at different levels of disaggregation, the highest of which includes roughly 220 price indexes, with observations available only since 1990 . The highest level of disaggregation for which it is possible to obtain data until the late seventies comprises 178 disaggregate prices and is used by Dolmas (2005). However, for the purpose of our analysis, the 178 series used by Dolmas (2005) correspond to an unnecessary high level of detail. Indeed, the goal of Dolmas (2005) is to construct an alternative price index, the so called Dallas Fed Trimmed Mean PCE, and therefore his aim is to have the highest level of disaggregation, conditional on data availability. By contrast, our goal is to compute the oil pass-through into core PCE prices, and therefore we have judgmentally chosen a lower level of aggregation comprising 88 price indexes (the complete list of series is available in Appendix 2). ${ }^{1}$ In this dataset $65 \%$ of the price indexes have a weight smaller than $\frac{1}{100}$, and just $16 \%$ of them have a weight larger than $\frac{2}{100}$.

To estimate the pass-through into the aggregates for core inflation we compute PCE weights as (see Dolmas, 2005, for details):

$$
w_{i, t+1}=0.5 \frac{Q_{i t} P_{i t}}{\sum Q_{i t} P_{i t}}+0.5 \frac{Q_{i, t+1} P_{i t}}{\sum Q_{i, t+1} P_{i t}},
$$

in which data for $Q_{i t}$ are taken from the NIPA Table 2.4.6U. In other words, the weights for the $i$-th item in, say, June 2016 is equal to an average of the expenditure share of that item in May 2016 and its expenditure share had it been bought in June 2016 at May 2016 prices. However, although PCE weights change every month, for the purpose of estimation of the oil price pass-through into core inflation we need just one set of weights, and we choose to pick the last one available, which are the weights for June $2016 .^{2}$

Finally, the oil price is measured by Refiners' Acquisition Cost of Crude Oil (RAC) as in, for example, Kilian and Vigfusson (2017). ${ }^{3}$ The data for RAC are from the U.S. Energy Information Administration and they were downloaded from Haver (PZRAC@USECON), while the data for core PCE price index, which were used to deflate the RAC, is from the NIPA table (ID 368, Name DPCCRX).

\subsection{Common and idiosyncratic dynamics in PCE prices}

The first question we need to answer is what is the main driver of disaggregate PCE prices? Common or idiosyncratic dynamics? To this end, we look at how much variance is explained by the first three common factors. The results reported here are obtained on a sample starting in 1984:M1 and ending in 2016:M6 (see Section 3.3 for a discussion on the choice of the sample).

1. In practice, we went component by component and we asked ourselves: "do we really need to further disaggregate this component?" In doing so we have been very careful and we opted for "no further disaggregation" only when it was a clear cut answer. For example, we have included the PCE price index for "Household supplies" rather than its 5 subcomponents: "Household cleaning products", "Household paper products", "Household linens", "Sewing items", and "Miscellaneous household products".

2. Note that this choice is somewhat arbitrary, but at the same time innocuous given that the weights change very slowly over time. For example, we have experimented with the equally acceptable alternative consisting in using the average weights instead of the most recent ones, and the results are nearly exactly the same.

3. An alternative would have been to use the West Texas Intermediate (WTI) spot crude oil price. However, as argued by Kilian (2016), retail gasoline prices depend on the Brent price, so the fact that refineries pay the lower WTI is irrelevant. Brent prices, however, are available only starting in 1987, and therefore we cannot use them in our benchmark sample which starts in 1984. 
Figure 1 shows the percentage of variance of each variable explained by the first three factors, where we have divided the disaggregate prices into four plots each of which represents a different category. If we look at food and energy (upper-left plot), which we expect to be driven to a great extent by sectoral factors, such as weather in the case of food and various supply shocks in the case of energy, we see that the second factor has good explanatory power thus suggesting that it captures mainly idiosyncratic food/energy related fluctuations. If we look at "Core Goods" prices (upper-right plot), "Core Services I" prices (lower-left plot), and "Core Services II (market based)" prices (lower-right plot), albeit few exceptions, the second, and the third factor have a very low explanatory power. Finally, the second factor has some explanatory power for non-marked based services.

\section{Figure 1: Common dynamics in PCE prices}
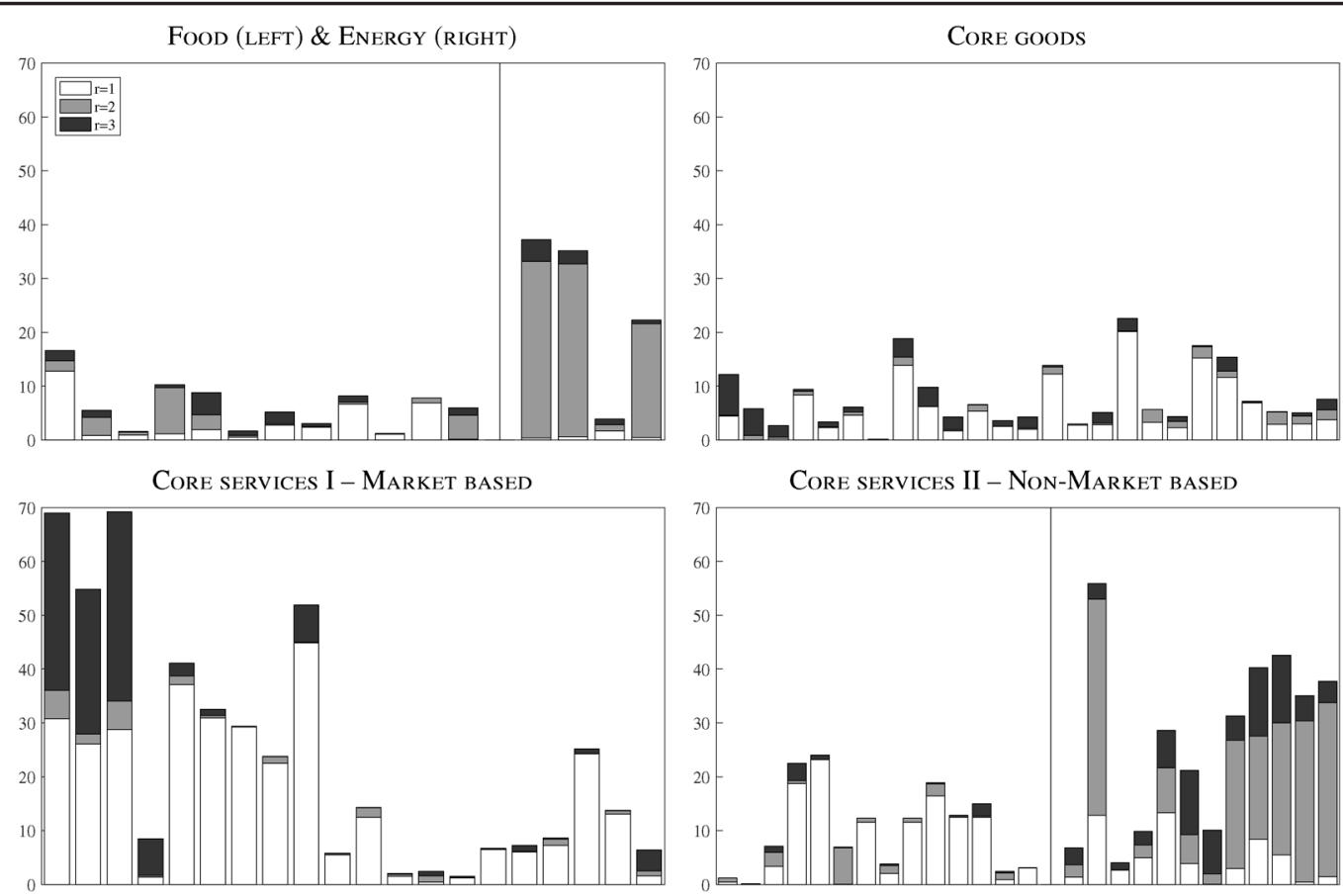

Notes: This figure shows the percentage of variance ( $y$-axis) of each variable ( $x$-axis) explained by the first three factors. Each bar represents a different disaggregate price. Core Services I includes: "Housing and utilities", "Health care", "Transportation services", "Recreation services", "Food services and accommodations". Core Services II includes: "Financial services and insurance", "Other services", and "Final consumption expenditures of NPISHs". To identify precisely each item, we refer the reader to the table in Appendix B.1 in which for each item we show the share of variance explained by the first factor (i.e., the white bars in the figure).

Table 1 reports the average percentage of variance of each price category explained by the first three factors computed using both monthly and quarterly inflation rates. ${ }^{4}$ These results clearly show that, no matter at which frequency (i.e., monthly or quarterly) we are looking at, (i) the bulk of the variance of disaggregate prices is explained by the first factor, (ii) the second factor is important only for energy while it is not relevant for core prices, and (iii) the third factor seems to matter only for non-market based services. 
Table 1: Common Dynamics in PCE Prices

\begin{tabular}{|c|c|c|c|c|c|c|}
\hline & \multicolumn{3}{|c|}{ Panel A: Monthly rates } & \multicolumn{3}{|c|}{ Panel B: Quarterly rates } \\
\hline & $r=1$ & $r=2$ & $r=3$ & $r=1$ & $r=2$ & $r=3$ \\
\hline Food & 3.2 & 2.0 & 1.2 & 8.2 & 2.4 & 2.1 \\
\hline Energy & 0.8 & 21.8 & 2.1 & 1.8 & 26.2 & 3.0 \\
\hline Goods & 5.5 & 0.8 & 1.6 & 13.3 & 1.4 & 2.8 \\
\hline Services (MB) & 13.2 & 1.2 & 3.8 & 22.4 & 1.5 & 4.2 \\
\hline Services (NMB) & 5.1 & 15.6 & 6.9 & 9.1 & 21.4 & 10.1 \\
\hline
\end{tabular}

Notes: This table reports the average (within category) percentage of variance of each variable explained by the first three factors. On Panel A the share of variance is computed using monthly inflation rates, i.e., $\pi_{i t}=1200 \times \Delta \log P_{i t}$ whereas in Panel B it is computed using quarterly inflation rates, i.e., $\pi_{i t}=400 \times\left(\log P_{i t}-\log P_{i t-3}\right)$. "Services (MB)" stand from market based Services, while "Services (NMB)" stand from non-market based Services

Table 2 reports the percentage of variance of the Core, Energy, and Food, PCE price index explained by the first three factors. As we can see, common dynamics accounts for about $50 \%$ of core PCE fluctuation.

Table 2: Common Dynamics in Aggregate PCE Prices

\begin{tabular}{lccc}
\hline & $r=1$ & $r=2$ & $r=3$ \\
\hline Core & 49.3 & 1.6 & 0.2 \\
Energy & 0.5 & 33.7 & 3.8 \\
Food & 9.6 & 5.0 & 3.5 \\
\hline
\end{tabular}

Notes: This table reports the percentage of variance of each Core, Energy, and Food, PCE price index explained by the first three factors.

Finally, Table 3 shows autocorrelations of the common factor and the idiosyncratic components. As we can see, the statistical properties of these two components are clearly different, as the idiosyncratic components are short-memory, whereas the common component is quite persistent. ${ }^{5}$

Table 3: Persistence of common and idiosyncratic dynamics

\begin{tabular}{lccc}
\hline & $\rho_{1}$ & $\rho_{6}$ & $\rho_{12}$ \\
\hline$\rho_{j}^{\xi}(50)$ & 0.12 & 0.07 & 0.06 \\
$\rho_{j}^{\xi}(75)$ & 0.22 & 0.12 & 0.12 \\
$\rho_{j}^{\xi}(90)$ & 0.38 & 0.21 & 0.21 \\
$\rho_{j}^{f}$ & 0.79 & 0.75 & 0.70 \\
\hline
\end{tabular}

Notes: This table shows the persistence of the idiosyncratic components and the common factor. In detail, $\rho_{j}^{\xi}(\alpha)$ is the $\alpha$ percentile of the distribution of the estimated autocorrelation coefficient at lag $j$ of the idiosyncratic component, while $\rho_{j}^{f}$ is the estimated autocorrelation coefficient at $\operatorname{lag} j$ for the common factor.

5. Note that the fact that disaggregate prices are more idiosyncratic than the aggregate index, and the fact that the idiosyncratic components are very volatile, are both in line with the theoretical results in Zaffaroni (2004). Zaffaroni (2004) shows that, as the number of variables gets large, the aggregation of univariate heterogeneous ARMA processes driven by a common and an idiosyncratic shock yields a time series that (1) is more persistent than the disaggregate series, and (2) is mainly driven by the common shock; by contrast the disaggregated series are mainly driven by the idiosyncratic shocks (see also Granger, 1980). For empirical results similar to ours, see Clark (2006) and Mackowiak et al. (2009) for the U.S., and Altissimo et al. (2009) and Beck et al. (2016) for the euro area. 
To sum up, and to answer the question we asked at the beginning of the section: although the main result emerging from Table 1, and Figure 1 is that idiosyncratic dynamics are the main driver of changes in disaggregate PCE prices (see also Boivin et al., 2009; Reis and Watson, 2010), as shown in Table 2 common and idiosyncratic dynamics are equally important in explaining fluctuations of the Core PCE price index.

\subsection{Results}

This Section presents estimates of the oil price pass-through into core PCE price inflation. Results for each of the 88 PCE price indexes in our dataset are available in an on-line appendix.

Our benchmark specification includes one factor $(r=1)$, and six lags in the VAR for the common factor (2), and likewise in all the VARs for the idiosyncratic components (3). Finally, the oil price shock is identified using a Choleski decomposition with the oil price ordered first. These choices deserve an explanation.

The results shown in Table 2 clearly point out that if the goal is to analyze core prices, then one factor suffices, as the second factor is primarily loaded by energy prices, and the third factor by non-market based services. Therefore, given that the existence of one factor is almost sure, and given that our goal are core PCE prices, we opted for a conservative approach choosing as our benchmark $r=1$. That said, we are perfectly aware that this choice contrasts with the common practice in the literature of including a larger number of factors when modeling PCE prices (see, e.g., Boivin et al., 2009, and Reis and Watson, 2010), and that it is at odds with the indication of the Bai and $\mathrm{Ng}$ (2002) information criteria, which support the choice of up to three common factors. However, in Appendix 1 we show robustness results when a larger number of factors is considered. Qualitatively, the main conclusions of this section are not affected. Quantitatively, the estimated response are just a touch higher, to the point that materially none of the conclusions change.

As for the number of lags in the VARs, the choice of six lags is in line with the existing literature (see for example Edelstein and Kilian, 2009; Gao et al., 2014). Indeed, although standard information criteria would select a smaller number of lags, we opted for a richer parametrization since several authors have pointed out that it is crucial to allow for long lags when estimating the transmission of oil price shocks.

As for identification of the oil price shock, a Choleski decomposition with the oil price ordered first corresponds to the identifying assumption that energy prices are predetermined with respect to the U.S. economy at monthly frequency (for a thorough discussion of this identification strategy see Kilian and Vega, 2011). In other words, in our framework an oil price shock is an unpredicted and unpredictable change in the oil price, and as such it has no "structural interpretation", that is we do not disentangle oil supply shocks from oil demand shocks (a non exhaustive list of papers that do so is: Kilian, 2008a, 2009b; Kilian and Murphy, 2012, 2014; Lippi and Nobili, 2012). ${ }^{6}$

The model is estimated on a sample starting in 1984:M1 and ending in 2016:M6, which contrasts with a large part of the literature on oil price shocks that uses samples starting in 1973/1974 (for example Kilian, 2009b; Aastveit, 2014; Gao et al., 2014). ${ }^{7}$ There are at least two good reasons to consider a sample starting in 1984 rather than 1974. First, it is well known that during the 1970s and the early 1980s inflation was much more volatile than afterwards. Second, several authors (for example Hooker, 2002; Clark and Terry, 2010) found a structural break in the oil-inflation relation

6. Note, however, that we have also estimated the model using the identification scheme proposed by Kilian (2009b), which disentangles between oil supply shock, oil demand shock, and global demand shock (see Appendix A.4).

7. Estimation over the 1974-2016 sample is considered in the robustness analysis presented in Section 3.4. 
in the early-mid eighties. ${ }^{8}$ For these reasons our sample starts in 1984 , the year considered by the literature as the start of the "great moderation".

Figure 2 shows the impulse response function to an oil price shock of both the percentage change, and the log-level, of the real oil price, together with a bootstrapped $90 \%$ confidence interval. After an unexpected 10\% increase, the real oil price increases further in the next two months by approximately $5.5 \%$ and $2 \%$, respectively, and then slowly decreases reaching a level that is about $13 \%$ higher than the pre-shock one.

Figure 2: Impulse response function to an oil price shock
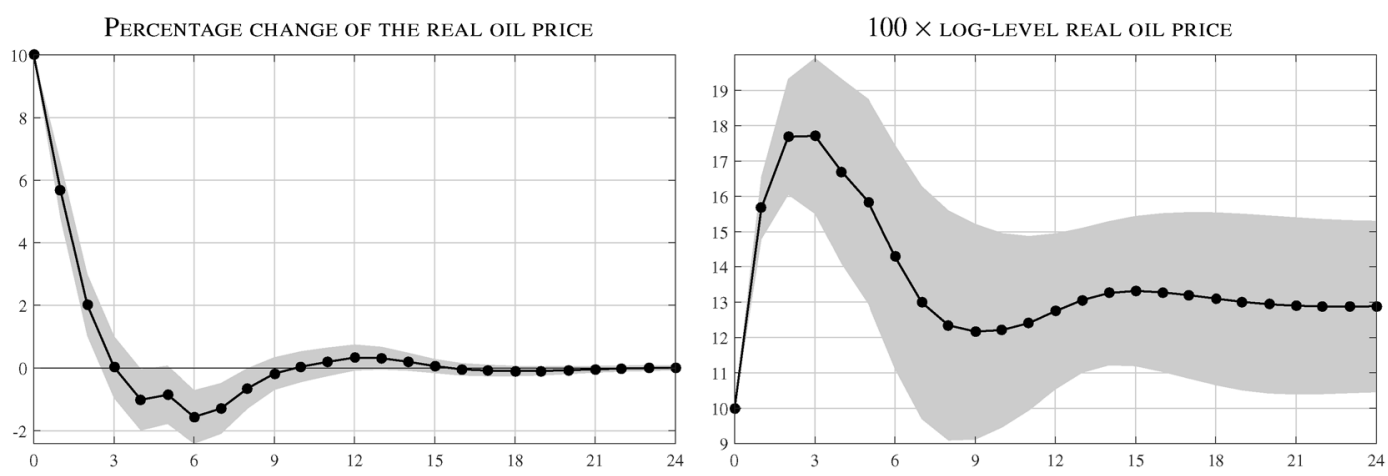

Notes: The left plot shows the impulse response function to an oil price shock of the percentage change of the real oil price price, while the right plot shows the log-level of the real oil price (multiplied by one-hundred). In each plot the straight line with markers is the point estimate while the shaded area are the $90 \%$ confidence bands. Note that the line in the right plot is the cumulative sum of the line in the left plot. Finally, the $x$-axis represents months, while the $y$-axis represents percentage points.

The left plot in Figure 3 shows the estimated oil price pass-through into the common component of core PCE price inflation, while the lower plots show the pass-through into the idiosyncratic component. As we can see, the pass-through of an unexpected $10 \%$ increase in the real oil price into the common component of core PCE prices, despite being small, is very persistent, as it is estimated to increase core PCE price inflation for more than 4 years (not shown here).

\section{Figure 3: Oil price pass-through into U.S. core PCE price inflation:}
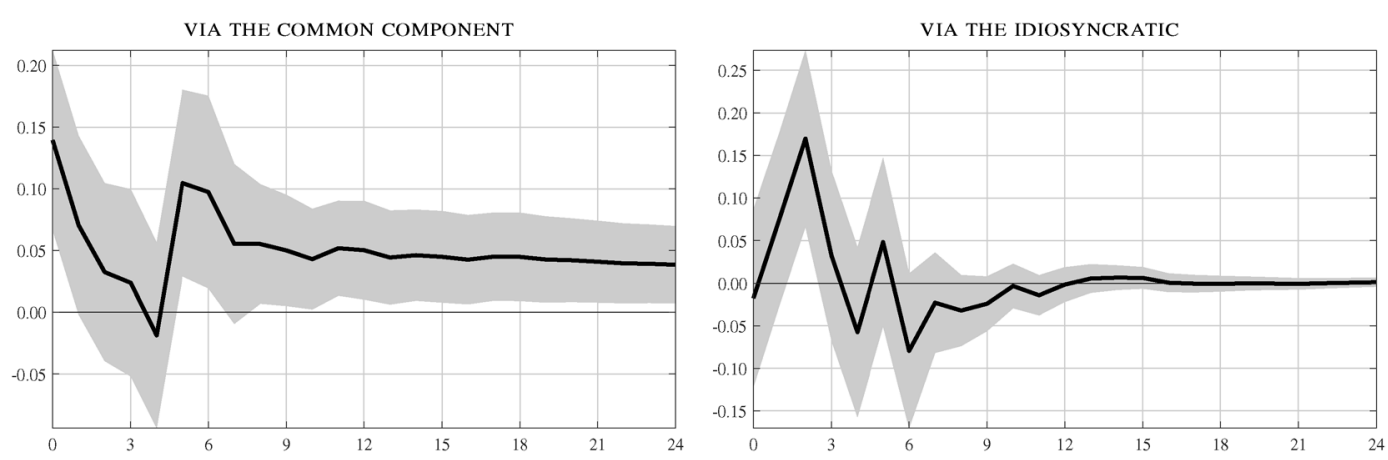

Notes: The left plot shows the pass-through of an unexpected $10 \%$ increase in the real oil price into the common component of core PCE prices, while the right plot shows the pass-through into the idiosyncratic component. On each plot the black line is the point estimate, while the shaded area is the $90 \%$ confidence band. The $x$-axis represents months, while the $y$-axis represents percentage points.

8. Note, however, that it might also be the case that the structural breaks are indeed spurious, and simply a consequence of the change over time of the composition of oil demand and oil supply shocks (e.g. Kilian, 2008a; Baumeister and Kilian, 2016), which has been shown have very different effects on the U.S. economy (e.g. Kilian, 2009b). 
By contrast, the pass-through into the idiosyncratic component is not significantly different from zero. Indeed, most of the idiosyncratic component are very erratic and noisy, and the only idiosyncratic pass-through that is statistically significant is the one of the index of "Air transportation", which has a weight of $\frac{0.5}{100}$ in core PCE.

In other words, the results in Figure 3 show that an oil price change passes-through core PCE prices only via its effect on the whole economy, while the direct effect via the cost channel is null.

Finally, having estimated the pass-through from oil prices to PCE price inflation, we can calculate what the oil price contribution to core PCE price inflation was. Figure 4 shows the average contribution per year of changes in the oil price to core inflation up to $2020 .{ }^{9}$ We estimate that the plunge in the Refinery Acquisition Cost from roughly $\$ 100$ per barrel to roughly $\$ 30$ per barrel that occurred between July 2014 to February 2016 shaved-off a third of a percentage point from core PCE price inflation in 2015, and four tenth of a percentage point in 2016. We estimate that the drag from oil prices will persist in 2017 and 2018 (about two tenth each year), and that it will then disappear by 2020 .

\section{Figure 4: Historical decomposition}

OIL PRICE CONTRIBUTION TO U.S. CORE PCE PRICE INFLATION

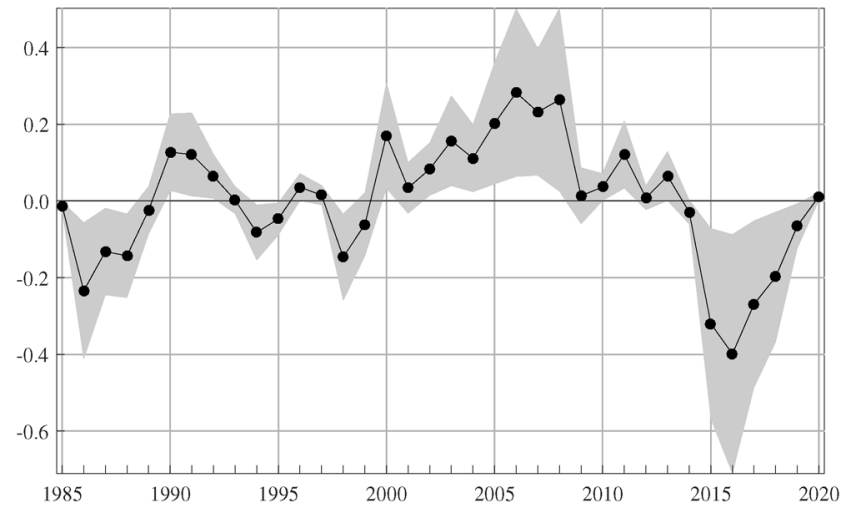

Notes: This plot shows the average contribution per year of real oil price changes to U.S. core PCE price inflation measured in percentage points ( $y$-axis). The black line with markers is the point estimate while the shaded area is the $90 \%$ confidence band.

\subsection{Has the oil price pass-through changed over time?}

There is extensive evidence that the oil price pass-through to core inflation has decreased over time (see Hooker, 2002; Chen, 2009, among others), with some authors finding that the passthrough has become negligible (Clark and Terry, 2010). Figure 5 shows the estimated pass-through into core PCE prices via the common component when the model is estimated on a longer sample starting in 1974 (left plot), and when the model is estimated on a shorter sample starting in 1996 (right plot), and Figure 6 shows the contribution of oil price shocks to core inflation estimated on the same subsamples. ${ }^{10}$

9. In details, Figure 4 shows the historical decomposition of the common component of core inflation. Note that, however, in Figure 4 we do not show the historical decomposition for the annualized monthly percentage change, rather we show the average per each year. And, given that we use log differences, this means that each dot in Figure 4 represent the part of the 12-month percentage change in December of year $j$ that is accounted for by the oil price.

10. The choice of 1996 is for comparison with the euro area analysis performed in Section 4, while 1974 is the starting date of a large number of empirical analysis (for example Aastveit, 2014; Gao et al., 2014). 
Figure 5: Has the oil price pass-through changed over time?

OIL PRICE PASS-THROUGH TO CORE INFLATION VIA THE COMMON COMPONENT

$1974-2016$

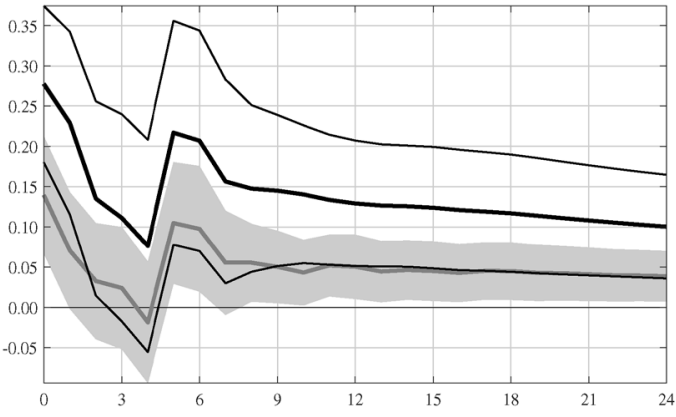

1996-2016

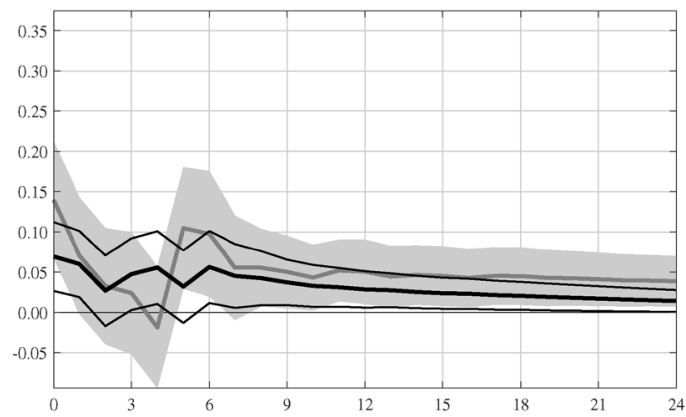

Notes: This figure shows the estimated pass-through of an unexpected $10 \%$ increase of the real oil price into the common component of core PCE prices. In each plot the gray line is the estimated pass-through in the benchmark model (the shaded area is the $90 \%$ confidence band), while the thick black line is the pass-through estimated on the sample starting in 1974 (left plot) or 1996 (right plot). The thin black lines are the 90 percent confidence bands for these alternative time periods. The $x$-axis represents months, while the $y$-axis represents percentage points.

By looking at Figure 5 we can see that, on the shorter sample, we estimate that a $10 \%$ increase in the oil price boosts inflation of about 7 basis points, about half of what we estimate on the full sample. In terms of historical decomposition, according to the estimates obtained on the 1996-2016 subsample, the oil price shocks shaved-off about a quarter of a percentage point in 2015, and two tenths of a percentage point in 2016 to core inflation, substantially less then estimated on the benchmark sample (Figure 6).

Figure 6: Has the oil price pass-through changed over time?

HiSTORICAL DECOMPOSITION

1974-2016

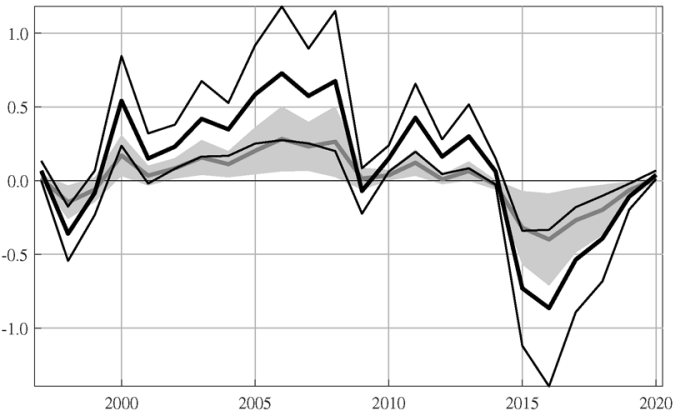

1996-2016

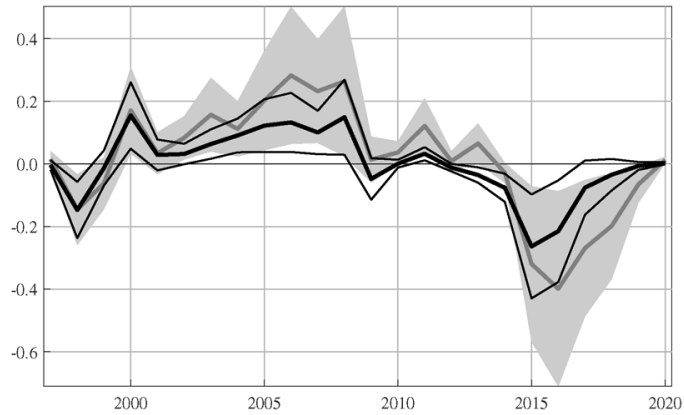

Notes: This figure shows the average contribution per year of real oil price changes to U.S. core PCE price inflation measured in percentage points ( $y$-axis). In each plot the gray line is the point estimate in the benchmark model (the shaded area is the $90 \%$ confidence band), while the thick black line is the point estimate on the sample starting in 1974 (left plot) or 1996 (right plot). The thin black lines are the 90 percent confidence bands for these alternative time periods.

In summary, the results in Figure 5 and Figure 6 confirm that the oil price pass-through into core inflation has decreased over time. However, in contrast with part of the literature (for example Clark and Terry, 2010), we find a statistically significant pass-through even on the sample starting in 1996. 
Why do we find a different result compared to the literature? The answer is that we disentangle common and idiosyncratic movement in price fluctuations, thus not letting the noisy idiosyncratic component affect our estimation. Indeed, had we estimated the pass-through into core PCE prices by ignoring the factor structure, we would have found a not significant pass-through (see Figure 7).

Figure 7: Has the oil price pass-through changed over time?

OIL PRICE PASS-THROUGH TO CORE INFLATION
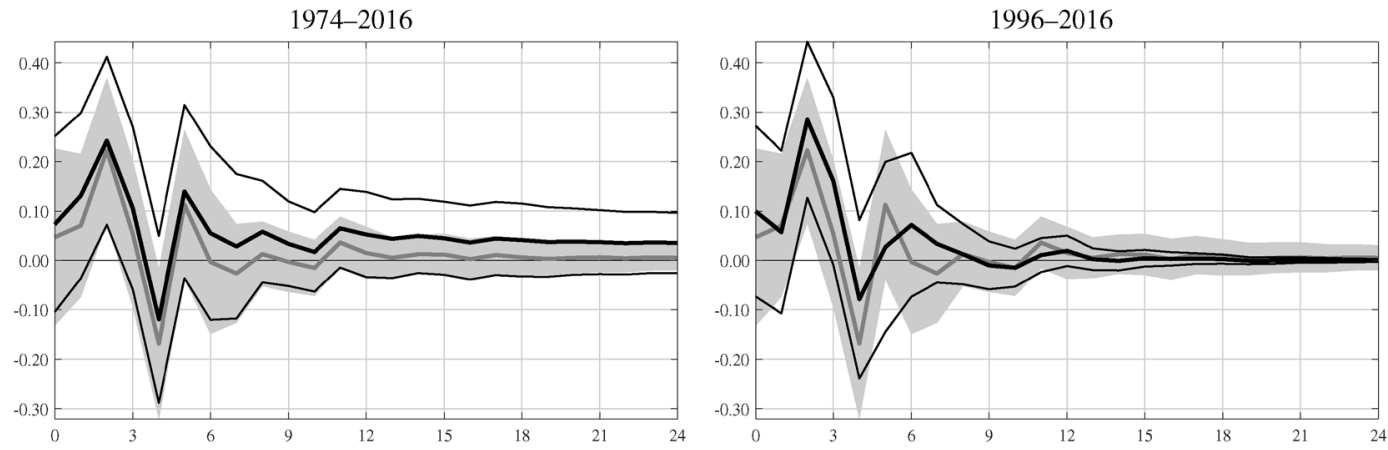

Notes: This figure shows the estimated pass-through into core PCE prices, i.e., $\pi_{t}^{\text {core }}=\chi_{t}^{\text {core }}+\xi_{t}^{\text {core }}$. In each plot the gray line is the estimated pass-through in the benchmark model (the shaded area is the $90 \%$ confidence band), while the thick black line is the pass-through estimated on the sample starting in 1974 (left plot) or 1996 (right plot). The thin black lines are the 90 percent confidence bands for these alternative time periods. The $x$-axis represents months, while the $y$-axis represents percentage points.

The literature has also asked why the pass-through has declined over time without, however, reaching an agreement. For example, a possible explanation is that part of the decline in the pass-through can be attributed to the adoption of energy-saving technologies (Hooker, 2002; Bachmeier and Cha, 2011). Moreover, Nordhaus (2007) and Bachmeier and Cha (2011) point towards a change in the monetary policy response to oil price shocks (see Blinder and Rudd, 2013, for a review), while Blanchard and Gali (2009) and Blanchard and Riggi (2013) to a large decrease of real wage rigidities in the U.S.. ${ }^{11}$ Finally, it might also be that the appearance of time variation in the response to an oil price shocks is simply an artifact due to the change over time of the composition of oil demand and oil supply shocks (e.g. Kilian, 2008a; Baumeister and Kilian, 2016), which has been shown to have very different effects on the U.S. economy (e.g. Kilian, 2009b).

Investigating properly the economic reasons of the decline in the pass-through into core inflation would require a structural model, therefore here we provide a reduced form explanation, namely: the degree of comovement in U.S. disaggregate prices has changed over time. Such an hypothesis is supported by the following empirical evidence: first, the average percentage of disaggregate prices fluctuation explained by the common component has decreased from $18 \%$ in the 1974-2016 sample, to 8\% in the 1984-2016 sample, to 6\% in the 1996-2016 sample (result not shown). Second, at the aggregate level, the common component accounts for $90 \%, 57 \%$, and $11 \%$ of core PCE fluctuations in the three samples, respectively. Finally, Figure 8 shows the pass-through obtained when the factor are extracted on a given sample, while the VAR (2) is estimated on a different sample. By looking at Figure 8 we can see that the magnitude of the estimated pass-through varies depending on which sample the factors are estimated, whereas the persistence of the estimated pass-through varies depending on which sample the VAR is estimated.

11. Note, however, that Kilian and Lewis (2011) provide evidence against these last two hypotheses. 
Figure 8: Why has the oil price pass-through changed over time?
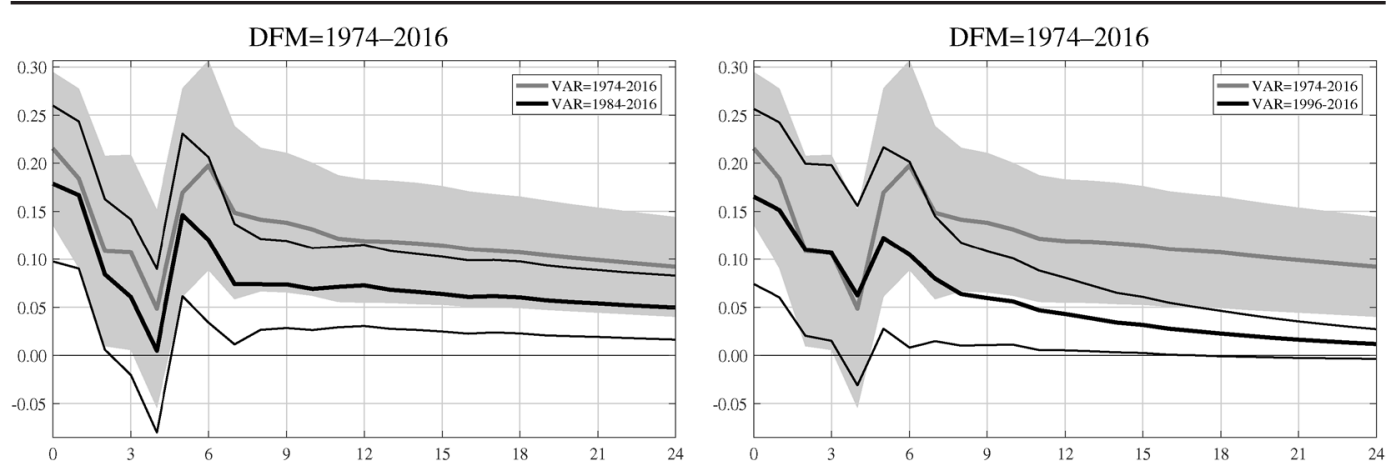

$\mathrm{DFM}=1984-2016$
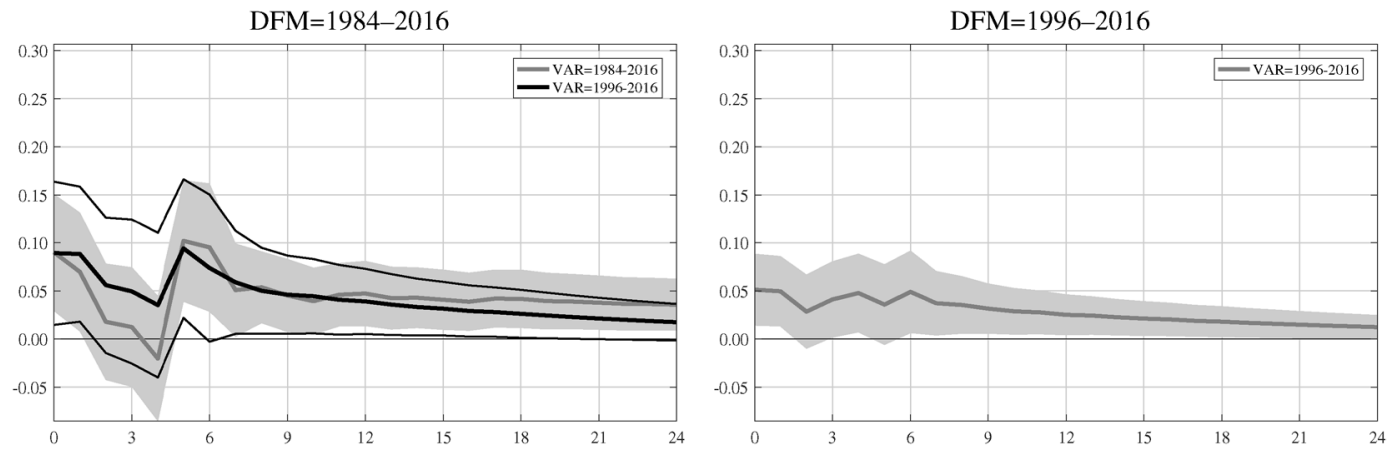

Notes: This figure shows the pass-through of an unexpected $10 \%$ increase in the real oil price into the common component together with $90 \%$ confidence bands. On each plot, the common factor is estimated over the sample specified in the title, while the VAR is estimated on the sample specified in the legend. The $x$-axis represents months, while the $y$-axis represents percentage points.

In conclusion, our reduced form analysis points out that one of the reasons why the oil price pass-through onto core inflation has decreased over time is the fact that disaggregate prices have increasingly been driven by idiosyncratic dynamics.

\section{OIL PRICE PASS-THROUGH IN THE EURO AREA}

\subsection{Data}

The price data for the euro area are monthly Harmonized Indexes of Consumer Prices (HICP) (see Appendix 2 for details), while the weights are the official HICP item weights referred to $2016 .{ }^{12}$ Both the disaggregate prices and the weights are available from Eurostat starting in 1996, and therefore the results for the euro area are obtained on a sample starting in 1996:M1, and ending in 2016:M6. Furthermore, given that Eurostat publishes seasonally adjusted series only for the aggregate indexes, we seasonally adjusted the disaggregated price series ourselves using X12 ARIMA.

HICP price indexes are available at 5-digit level Classification of Individual Consumption by Purpose (COICOP) for a total of 303 disaggregate prices. However, for the purpose of our analysis, 303 series correspond to an unnecessary high level of detail, and, therefore, we chose a

12. Weights of the Classification of Individual Consumption by Purpose (COICOP) categories are revised yearly and released in February together with the data for the month of January. In other words, while PCE weights change every month, HICP weights are constant within a given year. 
lower level of aggregation (3-digit level), which gives us a dataset of 95 series, roughly the same number of series as those used for the U.S.. ${ }^{13}$ From this 95 price dataset we remove the following components that are available only starting from January 2000: "Dental services", "Hospital services", "Social protection", "Other insurance", "Insurance connected with health", and "Medical and paramedical services". The final dataset is composed of 87 price series covering $96.1 \%$ of the HICP index with $69 \%$ of the price indexes that have a weight smaller than $\frac{1}{100}$, and $14 \%$ of them that have a weight larger than $\frac{2}{100}$.

Finally, the oil price is measured by the Brent spot crude oil price, which is deflated by the HICP core price index. The data for the Brent price are taken from the U.S. Energy Information Administration and the Wall Street Journal, and were downloaded from Haver (PEBRT@USECON), while the data for core HICP are taken from Eurostat (teicp200).

\subsection{Common and idiosyncratic dynamics in HICP prices}

Figure 9 shows the percentage of variance of each variable explained by the first three factors, where we have divided the disaggregate prices into three plots each of which represents a different category. As we can see, the second factors matters just for a few core goods prices, and for energy prices, whereas the third factor matters only for a handful of core prices.

Figure 9: Common dynamics in euro area HICP prices
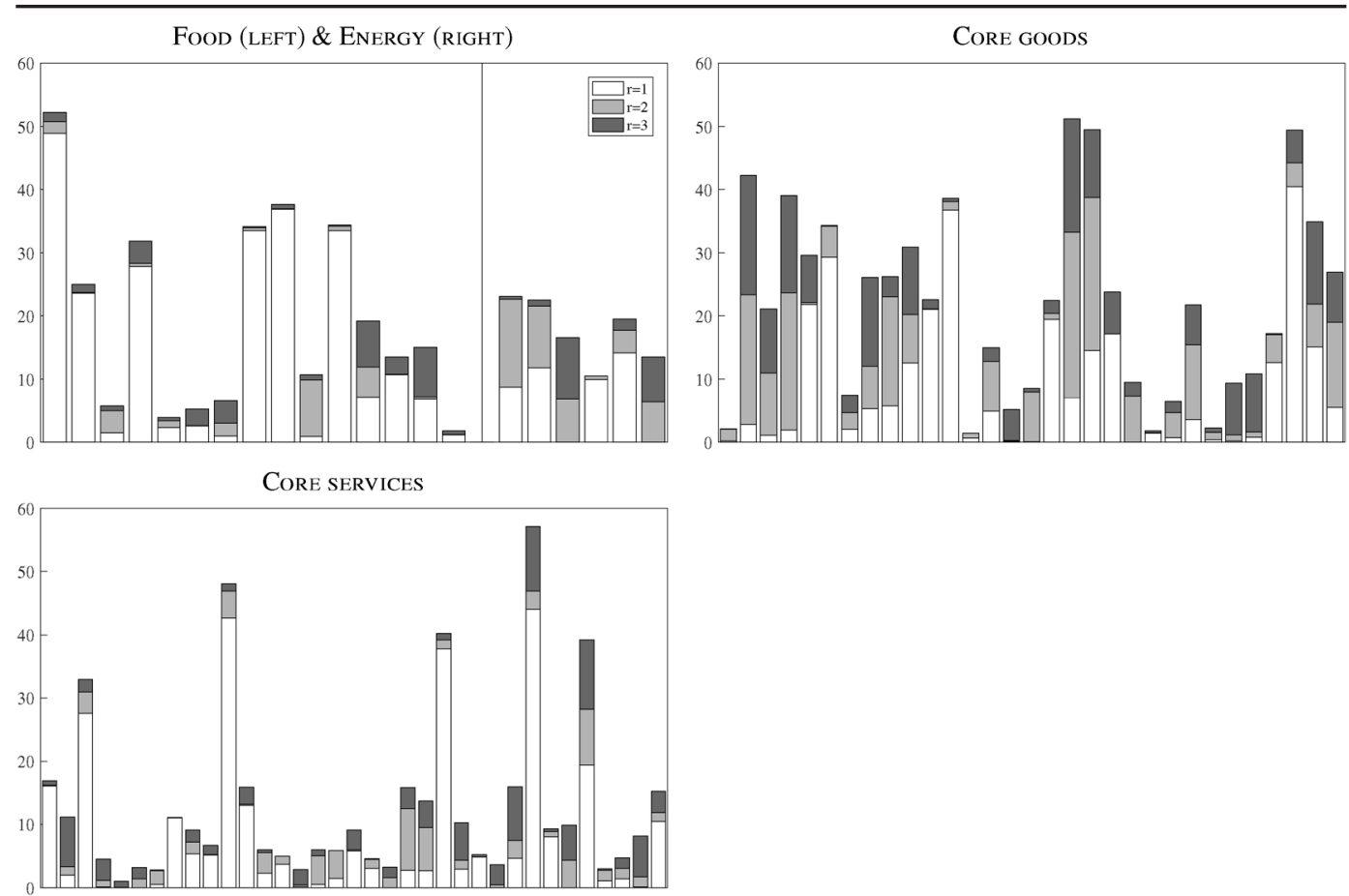

Notes: This figure shows the percentage of variance ( $y$-axis) of each variable ( $x$-axis) explained by the first three factors. Each bar represents a different disaggregate price. To identify precisely each item, we refer the reader to the table in Appendix B.2 in which for each item we show the share of variance explained by the first factor (i.e., the white bars in the figure).

13. Furthermore, note that for many countries in the euro area the 5-digit decomposition is not available prior to 2005. 
Finally, as was the case for U.S. PCE prices, although idiosyncratic dynamics dominate disaggregated prices' fluctuation, they are less important for the evolution of the aggregate core index. Indeed, in a model with one common factor, the common component accounts for $21 \%$ of core euro area HICP inflation fluctuations, which is comparable to the shares estimated for U.S. PCE prices on the 1996-2016 sample, which is $11 \%$.

\subsection{Results}

In this Section we present estimates of the oil price pass-through into core euro area HICP inflation. The benchmark specification is identical to the one used for U.S. PCE prices, that is one factor $(r=1)$, six lags in the VARs (2) and (3), and oil price shocks identified using a Choleski decomposition with the oil price ordered first.

Figure 10 reports the estimated oil price pass-through into the common (left) and the idiosyncratic (right) component of core HICP prices, together with $90 \%$ bootstrap confidence bands. The estimated pass-through into core HICP inflation in the euro area is similar to that estimated for the U.S.: the pass-through via the idiosyncratic component is not statistically different from zero, while the pass-through via the common component is null in the current month, but then small and persistent. ${ }^{14}$

\section{Figure 10: Oil price pass-through into euro area HICP inflation}
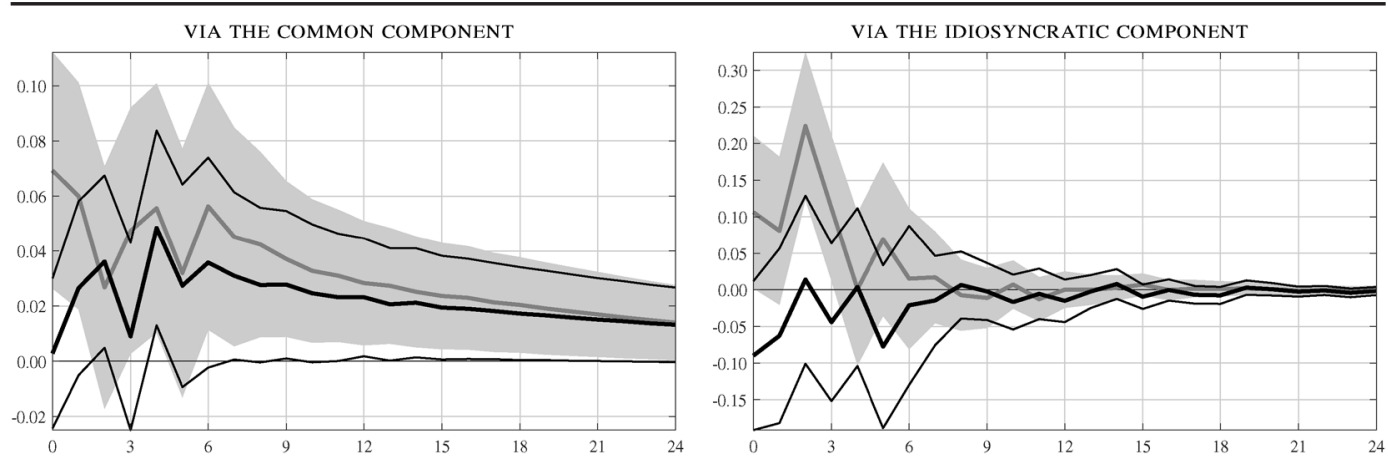

Notes: The left plot shows the pass-through of an unexpected $10 \%$ increase in the real oil price into the common component of core HICP prices, while the right plot shows the pass-through into the idiosyncratic component. On each plot the thick black line is the point estimate for the euro area, while the thin black lines are the $90 \%$ confidence bands. Likewise, the solid gray line and the shaded area are the point estimate and the confidence bands for the U.S., respectively. The $x$-axis represents months after the oil price increase, while the $y$-axis represents percentage points.

Figure 11 shows the oil price contribution to core euro area HICP inflation up to 2020 (see also footnote 3). We estimate that the 2014-2016 plunge in the oil price shaved-off approximately a quarter of a percentage point from core inflation in the euro area in 2015, and two tenth of a percentage point in 2016. The drag from oil prices will persist in 2017 and 2018 (6 and 3 basis points, respectively), but it will fade away by $2019 .{ }^{15}$ These numbers are very similar to those estimated for the U.S.

14. Note that the estimated pass-through via the idiosyncratic component in the U.S. in the 1996-2016 sample is statistically different from zero in the first few months. However, this result is spurious as it is mainly driven by the estimated pass-through on the price index for gambling. The PCE price index for gambling, which is a non-market based service, it is computed by the BEA using the CPI all-item. Therefore, given that part of the CPI-all item is the Energy CPI, which in its turn is very much correlated with the oil price, the fact that the index for Gambling respond to oil price shocks is purely spurious and due to the way that specific index is calculated.

15. In a recent paper Conti et al. (2017) estimate that oil prices shaved off an average of (roughly) 13 basis points from euro area core inflation. Such an estimate is lower but not statistically different than ours. 


\section{Figure 11: Historical decomposition}

OIL PRICE CONTRIBUTION TO EURO AREA CORE HICP INFLATION

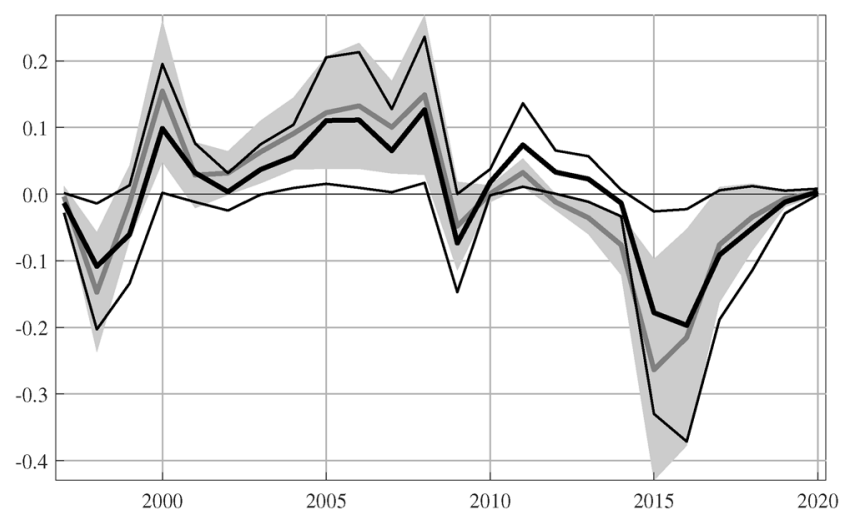

Notes: This plot shows the average contribution per year of real oil price changes to euro area core HICP inflation measured in percentage points ( $y$-axis). The thick black line is the point estimate for the euro area while the thin black lines area are the $90 \%$ confidence bands). Likewise, the solid gray line and the shaded area are the point estimate and the confidence band for the U.S., respectively.

\section{CONCLUSIONS}

In this paper we estimate the oil price pass-through into consumer prices both in the U.S. and in the euro area. To do so, we use a novel econometric approach based on dynamic factor models and VARs, which allow us to distinguish between the specific (idiosyncratic) effect that oil price changes might have on each disaggregate price, from the macroeconomic (common) effect that oil price changes might have since they contribute to macroeconomic fluctuations.

Our results show that oil price change passes-through core PCE prices only via its effect on the whole economy, while the direct effect via the cost channel is null. As a results oil price fluctuations have a limited but long lasting effect on core inflation. According to our estimates the plunge of oil prices from July 2014 to February 2016 shaved-off just a couple of tenths of a percentage point from core inflation in both the U.S. and the euro area.

\section{ACKNOWLEDGMENTS}

We are grateful to three anonymous referees, Stephanie Aaronson, Jonas Arias, Riccardo Cristadoro, Reinhard Ellwanger, Kirstin Hubirch, Stefano Neri, Jeremy Rudd, Stefano Siviero, Fabrizio Venditti, and Giovanni Veronese for excellent, helpful comments. This paper has benefited also from discussions with participants at the 2017 Simposio of the Spanish Economic Association, the 2017 Day-Ahead System Energy Meeting, the 32nd Annual Congress of the European Economic Association, and the IJCB conference on "Commodity Prices and Monetary Policy: New Theory and Evidence". The views expressed in this paper are those of the authors and do not necessarily reflect the views and policies of the Banca d'Italia or the Eurosystem, and of the Board of Governors or the Federal Reserve System.

\section{REFERENCES}

Aastveit, K.A. (2014). "Oil price shocks in a data-rich environment." Energy Economics 45: 268-279. https://doi. org/10.1016/j.eneco.2014.07.006. 
Aastveit, K.A., H.C. Bjørnland, and L.A. Thorsrud (2015). "What Drives Oil Prices? Emerging Versus Developed Economies.” Journal of Applied Econometrics 30: 1013-1028. https://doi.org/10.1002/jae.2406.

Altissimo, F., B. Mojon, and P. Zaffaroni (2009). “Can aggregation explain the persistence of inflation?” Journal of Monetary Economics 56: 231-241. https://doi.org/10.1016/j.jmoneco.2008.12.013.

An, L., X. Jin, and X. Ren (2014). "Are the macroeconomic effects of oil price shock symmetric? A Factor-Augmented Vector Autoregressive approach.” Energy Economics 45: 217-228. https://doi.org/10.1016/j.eneco.2014.06.003.

Bachmeier, L.J. and I. Cha (2011). "Why Don't Oil Shocks Cause Inflation? Evidence from Disaggregate Inflation Data." Journal of Money, Credit and Banking 43: 1165-1183. https://doi.org/10.1111/j.1538-4616.2011.00421.x.

Bai, J. (2003). "Inferential theory for factor models of large dimensions." Econometrica 71: 135-171. https://doi. org/10.1111/1468-0262.00392.

Bai, J. (2004). "Estimating cross-section common stochastic trends in nonstationary panel data." Journal of Econometrics 122: 137-183. https://doi.org/10.1016/j.jeconom.2003.10.022.

Bai, J. and S. Ng (2002). "Determining the number of factors in approximate factor models." Econometrica 70: $191-221$. https://doi.org/10.1111/1468-0262.00273.

Bai, J. and S. Ng (2004). “A PANIC Attack on Unit Roots and Cointegration.” Econometrica 72: 1127-1177. https://doi. org/10.1111/j.1468-0262.2004.00528.x.

Barigozzi, M., M. Lippi, and M. Luciani (2016). "Non-Stationary Dynamic Factor Models for Large Datasets.” FEDS 2016018 Board of Governors of the Federal Reserve System. https://doi.org/10.2139/ssrn.2741739.

Baumeister, C. and L. Kilian (2016). "Lower Oil Prices and the U.S. Economy: Is This Time Different?” Brookings Papers on Economic Activity: 287-336. https://doi.org/10.1353/eca.2016.0029.

Baumeister, C., L. Kilian, and X. Zhou (2018). “Is the Discretionary Income Effect of Oil Price Shocks a Hoax?” The Energy Journal 39: 117-137. https://doi.org/10.5547/01956574.39.SI2.cbau.

Beck, G.W., K. Hubrich, and M. Marcellino (2016). "On the importance of sectoral and regional shocks for price setting." Journal of Applied Econometrics 31: 1234-1253. https://doi.org/10.1002/jae.2490.

Bernanke, B.S., J. Boivin, and P.S. Eliasz (2005). "Measuring the Effects of Monetary Policy: A Factor-Augmented Vector Autoregressive (FAVAR) Approach.” The Quarterly Journal of Economics 120: 387-422. https://doi. org/10.1162/0033553053327452.

Blanchard, O. J. and J. Gali (2009). "The Macroeconomic Effects of Oil Price Shocks: Why are the 2000s so different from the 1970s?” in J. Gali and M. J. Gertler (editors), “International Dimensions of Monetary Policy,” National Bureau of Economic Research, Inc 373-421. https://doi.org/10.7208/chicago/9780226278872.003.0008.

Blanchard, O.J. and M. Riggi (2013). "Why are the 2000s so different from the 1970s? A structural interpretation of changes in the macroeconomic effects of oil prices." Journal of the European Economic Association 11: 1032-1052. https://doi. org/10.1111/jeea.12029.

Boivin, J., M.P. Giannoni, and I. Mihov (2009). "Sticky Prices and Monetary Policy: Evidence from Disaggregated US Data." American Economic Review 99: 350-384. https://doi.org/10.1257/aer.99.1.350.

Bruno, M. and J. Sachs (1985). Economics of Worldwide Stagflation. Harvard University Press, Cambridge, MA. https://doi. org/10.4159/harvard.9780674493049.

Burdette, M. and J. Zyren (2003). “Gasoline Price Pass-Through.” Energy Information Agency, U.S. Department of Energy, Washington, D.C. http://www.eia.gov/pub/oil_gas/petroleum/feature_articles/2003/gasolinepass/gasolinepass.htm.

Clark, T.E. (2006). "Disaggregate evidence on the persistence of consumer price inflation." Journal of Applied Econometrics 21: 563-587. https://doi.org/10.1002/jae.859.

Clark, T.E. and S. Terry (2010). "Time Variation in the Inflation Passthrough of Energy Prices." Journal of Money, Credit and Banking 42: 1419-1433. https://doi.org/10.1111/j.1538-4616.2010.00347.x.

Conti, A.M., S. Neri, and A. Nobili (2017). "Low inflation and monetary policy in the euro area.” Working Paper 2005 European Central Bank.

Dolmas, J. (2005). “Trimmed mean PCE inflation.” Working Paper 506 Federal Reserve Bank of Dallas.

Edelstein, P. and L. Kilian (2007). "The Response of Business Fixed Investment to Changes in Energy Prices: A Test of Some Hypotheses about the Transmission of Energy Price Shocks.” The B.E. Journal of Macroeconomics 7: 1-41. https://doi. org/10.2202/1935-1690.1607.

Edelstein, P. and L. Kilian (2009). "How sensitive are consumer expenditures to retail energy prices?” Journal of Monetary Economics 56: 766-799. https://doi.org/10.1016/j.jmoneco.2009.06.001.

Forni, M., D. Giannone, M. Lippi, and L. Reichlin (2009). "Opening the black box: Structural factor models versus structural VARs.” Econometric Theory 25: 1319-1347. https://doi.org/10.1017/S026646660809052X.

Forni, M., M. Hallin, M. Lippi, and L. Reichlin (2000). "The Generalized Dynamic Factor Model: Identification and estimation." The Review of Economics and Statistics 82: 540-554. https://doi.org/10.1162/003465300559037. 
Forni, M. and M. Lippi (2001). “The Generalized Dynamic Factor Model: Representation Theory.” Econometric Theory 17: 1113-1141. https://doi.org/10.1017/S0266466601176048.

Gao, L., H. Kim, and R. Saba (2014). "How do oil price shocks affect consumer prices?” Energy Economics 45: $313-323$. https://doi.org/10.1016/j.eneco.2014.08.001.

Giannone, D., L. Reichlin, and L. Sala (2005). "Monetary Policy in Real Time” in M. Gertler and K. Rogoff (editors), "NBER Macroeconomics Annual 2004,” MIT Press. https://doi.org/10.2139/ssrn.680521.

Hooker, M.A. (2002). “Are Oil Shocks Inflationary? Asymmetric and Nonlinear Specifications versus Changes in Regime.” Journal of Money, Credit and Banking 34: 540-561. https://doi.org/10.1353/mcb.2002.0041.

Juvenal, L. and I. Petrella (2015). "Speculation in the Oil Market.” Journal of Applied Econometrics 30: 1099-1255. https:// doi.org/10.1002/jae.2388.

Kilian, L. (2009). "Not All Oil Price Shocks Are Alike: Disentangling Demand and Supply Shocks in the Crude Oil Market." American Economic Review 99: 1053-1069. https://doi.org/10.1257/aer.99.3.1053.

Kilian, L. (2014). “Oil Price Shocks: Causes and Consequences.” Annual Review of Resource Economics 6: 133-154. https:// doi.org/10.1146/annurev-resource-083013-114701.

Kilian, L. (2016). "The Impact of the Shale Oil Revolution on U.S. Oil and Gasoline Prices.” Review of Environmental Economics and Policy 10: 185-205. https://doi.org/10.1093/reep/rew001.

Kilian, L. and L.T. Lewis (2011). “Does the Fed Respond to Oil Price Shocks?” The Economic Journal 121: $1047-1072$. https://doi.org/10.1111/j.1468-0297.2011.02437.x.

Kilian, L. and R.J. Vigfusson (2017). "The Role of Oil Price Shocks in Causing U.S. Recessions.” Journal of Money, Credit, and Banking 49: 1747-1776. https://doi.org/10.1111/jmcb.12430.

Luciani, M. (2015). "Monetary Policy and the Housing Market: A Structural Factor Analysis.” Journal of Applied Econometrics 30: 199-218. https://doi.org/10.1002/jae.2318.

Maćkowiak, B., E. Moench, and M. Wiederholt (2009). "Sectoral price data and models of price setting." Journal of Monetary Economics 56: 78-99. https://doi.org/10.1016/j.jmoneco.2009.06.012.

Meyler, A. (2009). "The pass through of oil prices into euro area consumer liquid fuel prices in an environment of high and volatile oil prices.” Energy Economics 31: 867-881. https://doi.org/10.1016/j.eneco.2009.07.002.

Nordhaus, W.D. (2007). "Who's Afraid of a Big Bad Oil Shock?” Brookings Papers on Economic Activity : 219-324. https:// doi.org/10.1353/eca.2008.0013.

Reis, R. and M.W. Watson (2010). "Relative Goods' Prices, Pure Inflation, and the Phillips Correlation.” American Economic Journal Macroeconomics 2: 128-157. https://doi.org/10.1257/mac.2.3.128.

Stock, J.H. and M.W. Watson (2002a). "Forecasting using principal components from a large number of predictors." Journal of the American Statistical Association 97: 1167-1179. https://doi.org/10.1198/016214502388618960.

Stock, J.H. and M.W. Watson (2002b). "Macroeconomic forecasting using diffusion indexes." Journal of Business and Economic Statistics 20: 147-162. https://doi.org/10.1198/073500102317351921.

Stock, J.H. and M.W. Watson (2005). "Implications of Dynamic Factor Models for VAR Analysis.” Working Paper 11467 National Bureau of Economic Research. https://doi.org/10.3386/w11467.

Stock, J.H. and M.W. Watson (2016). "Dynamic Factor Models, Factor-Augmented Vector Autoregressions, and Structural Vector Autoregressions in Macroeconomics." in J. B. Taylor and H. Uhlig (editors), "Handbook of Macroeconomics," volume 2 Elsevier 415-525. https://doi.org/10.1016/bs.hesmac.2016.04.002.

Wu, J.C. and F.D. Xia (2016). "Measuring the Macroeconomic Impact of Monetary Policy at the Zero Lower Bound.” Journal of Money, Credit, and Banking 48: 253-291. https://doi.org/10.1111/jmcb.12300.

Zaffaroni, P. (2004). "Contemporaneous aggregation of linear dynamic models in large economies" Journal of Econometrics 120: 75-102. https://doi.org/10.1016/S0304-4076(03)00207-0.

\section{APPENDIX 1. ROBUSTNESS ANALYSIS}

In this section we provide robustness checks for the U.S.

\section{A.1 Different number of factors}

As explained in Section 3.2 there is considerable uncertainty on the number of factors to be included in the model, and in the first robustness check we show results with a larger number of 
factors included. Figure A1 reports results when $r=3$ as in Reis and Watson (2010). In a nutshell: results for core PCE prices are qualitatively unchanged, while quantitatively just a touch higher.

\section{Figure A1: Robustness analysis with respect to number of factors}

OIL PRICE PASS-THROUGH INTO U.S. PCE PRICE INFLATION
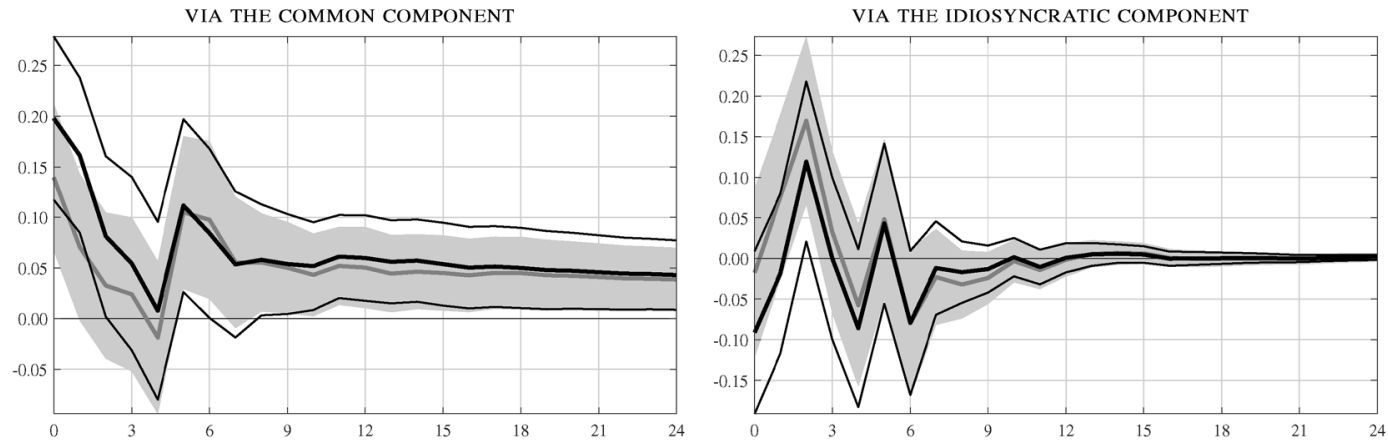

Notes: The left plot shows the pass-through of an unexpected $10 \%$ increase in the real oil price into the common component, while the right plot shows the pass-through into idiosyncratic component. On each plot the gray line is the estimated passthrough in the benchmark model (the shaded area is the $90 \%$ confidence band), while the black line is the pass-through estimated when $r=3$ (the dashed black lines are the $90 \%$ confidence bands). The $x$-axis represents months, while the $y$-axis represents percentage points.

\section{A.2 DFM vs. FAVAR}

As explained in Section 2 our model is very similar to a standard FAVAR model (Bernanke et al., 2005). In our model, the oil price is expected to have not only a common effect on all prices, but also to possibly have an idiosyncratic effect on energy intensive items. In a FAVAR model, instead, the oil price is treated as an observed factor, which means that the oil price is part of the common space only, and it has no effects on the idiosyncratic component. In formulas, equation (1) is replaced by

$$
\pi_{i t}=\lambda_{i}^{\prime} \mathbf{f}_{t}+\gamma_{i} y_{t}+\xi_{i t}
$$

while (2) remains equal and the idiosyncratic component is not modeled. By substituting (2) into (1) we can derive the oil price pass-through into the inflation rate of price $i$ implied by the FAVAR as:

$$
\tilde{\psi}_{i}(L)=\lambda_{i}^{\prime} \mathbf{c}_{i 12}(L)+\gamma_{i} c_{i 22}(L) \text {. }
$$

Now, in principle $\tilde{\psi}_{i}(L)$ should be equal to $\tilde{\psi}_{i}^{\chi}(L)$, and $\tilde{\psi}_{i}^{\xi}(L)$ should be zero, as in a FAVAR model the oil price is treated as an observed factor. However, with a clear and acknowledged abuse of notation, we are going to write $\tilde{\psi}_{i}^{\chi}(L)=\lambda_{i} \mathbf{c}_{i 12}(L)$ and $\tilde{\psi}_{i}^{\xi}(L)=\gamma_{i} c_{i 22}(L)$, and then by comparing (2) with (4) we can see that $\tilde{\psi}_{i}^{\chi}(L)=\psi_{i}^{\chi}(L)$, and $\tilde{\psi}_{i}^{\xi}(L) \not \psi_{i}^{\xi}(L)$.

Figure A2 compares our benchmark estimated oil price pass-through with the one estimated using a FAVAR.${ }^{16}$ More precisely, the left plot of Figure A2 shows the pass-through into the com-

16. The FAVAR is estimated using PCA and OLS. More specifically, we follow Boivin et al. (2009) and Aastveit (2014) and we first estimate $\mathbf{f}_{t}$ by PCA, call it $\hat{\mathbf{f}}_{t}^{0}$, and then we iterate between (1) estimate $\boldsymbol{\lambda}_{i}$ and $\gamma_{i}$ by regressing $x_{i t}$ into $\hat{\mathbf{f}}_{t}^{j-1}$ and $y_{t}$, and (2) estimate $\hat{\mathbf{f}}_{t}^{j}$ by PCA on $\tilde{\mathbf{x}}_{t}=\mathbf{x}_{t}-\hat{\gamma}^{j} y_{t}$. Alternatively a FAVAR could be estimated in one shot either by estimating a restricted DFM with Maximum Likelihood as in Juvenal and Petrella (2015) and Luciani (2015), or with Bayesian method as in Bernanke et al. (2005). 
mon component, while the right plot shows the pass-through into the idiosyncratic component. As expected, the estimated pass-through into the common component is identical, while the estimated idiosyncratic pass-through is similar. All in all, the results in Figure A4 show that had we estimated a standard FAVAR rather than the model in Section 2 we would have reached the same conclusions.

\section{Figure A2: Robustness analysis with respect to model structure}

OIL PRICE PASS-THROUGH INTO U.S. PCE PRICE INFLATION
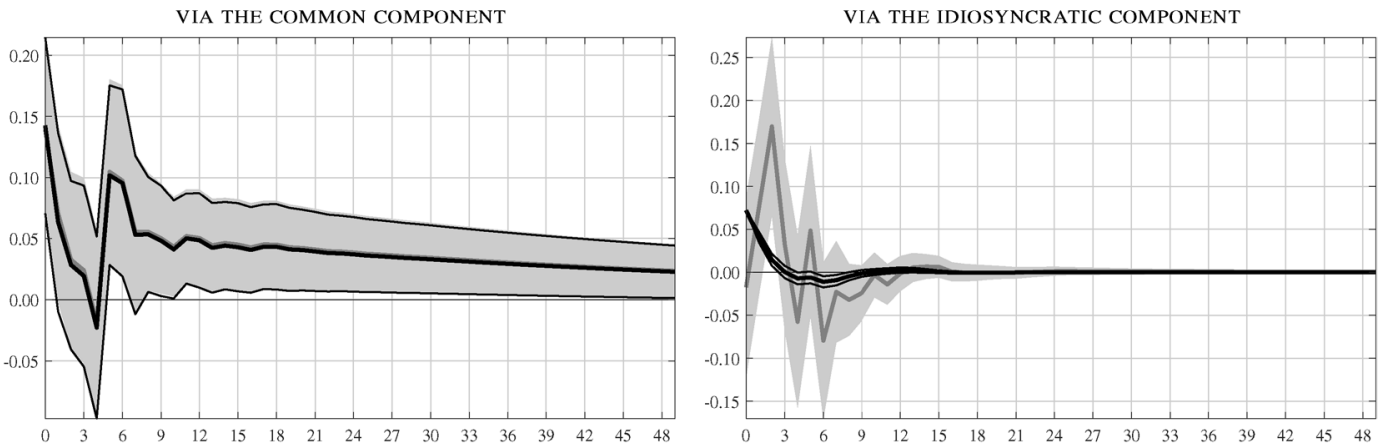

Notes: The left plot shows the pass-through of an unexpected $10 \%$ increase in the real oil price into the common component $\left(\boldsymbol{\lambda}_{i}^{\prime} \mathbf{c}_{i 12}(L)\right)$, while the right plot shows the pass-through into the idiosyncratic component $\left(d_{i 12}(L)\right.$ for the benchmark model, and $\gamma_{i} c_{i 22}(L)$ for the FAVAR). On each plot the gray line is the estimated pass-through in the benchmark model (the shaded area is the $90 \%$ confidence band), while the black line is the pass-through estimated with the FAVAR (the dashed black lines are the $90 \%$ confidence bands). The $x$-axis represents months, while the $y$-axis represents percentage points.

\section{A.3 Alternative VAR system}

Our model assumes that the comovement in PCE prices is driven by two shocks: a common shock, which has no structural interpretation, and an oil price shock. This is clearly a simplifying assumption as the common component might reflect the interplay of several different sources of macroeconomic fluctuations, such as monetary policy shocks, for example. Does this simplifying assumption bias our results? Are we making a mistake in not disentangling these different sources? This Section answers these questions.

In order to account for the interplay of different macroeconomic forces, we estimate a larger VAR model. In detail, we first estimate equation (1), and then, rather than estimating the VAR (2), we estimate a four-variable VAR including the percentage change in the real oil price $\left(y_{t}\right)$, the unemployment rate, the Fed funds rate, and the common factor $\left(f_{t}\right) \cdot{ }^{17}$

The left plot in Figure A3 compares the oil price pass-through into core inflation estimated with the larger VAR (black line) to that estimated with the benchmark model (gray line). Results are essentially unchanged: the estimated pass-through with the enlarged VAR is just a touch smaller than the one estimated with the benchmark model. In other words, the main conclusion of the paper is confirmed - the oil price pass-through to core inflation is small but statistically significant and long lasting.

\section{Figure A3: Alternative VAR system}

17. The unemployment rate is the "Civilian Unemployment Rate: $16 \mathrm{yr}+$ " from the Bureau of Labor Statistics, while the Fed Funds Rate is from the Federal Reserve Board. Note that, for the period in which the Fed funds rate hit the zero lower we, we replace the Fed funds rate with the Wu and Xia (2016) shadow rate. These series where downloaded from Haver (LR@) USECON, FFED@USECON, and FFEDSHDW@USECON). 

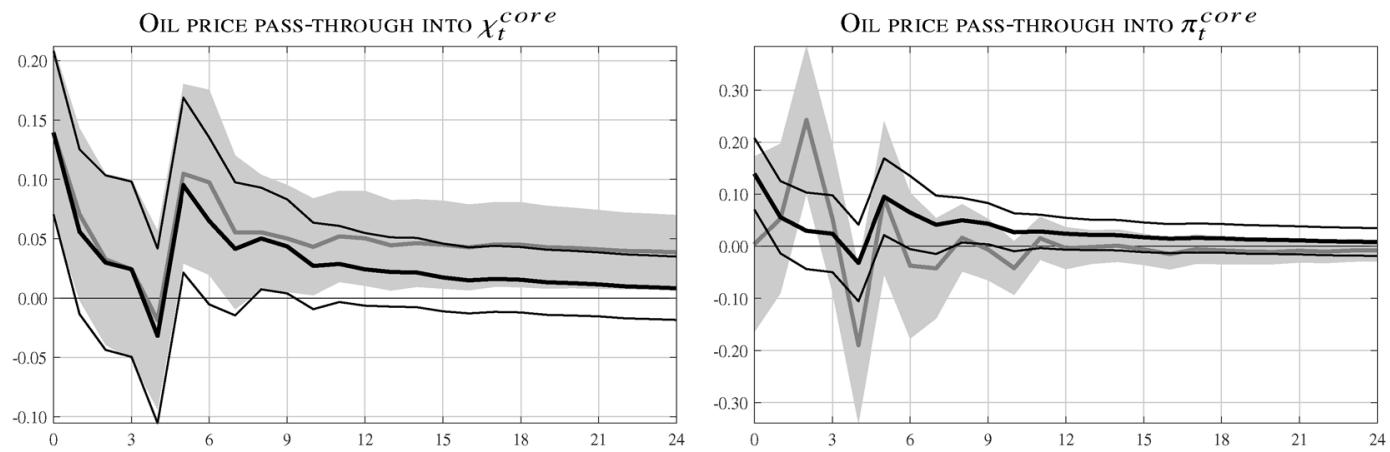

Notes: The left plot shows the pass-through of an unexpected $10 \%$ increase of the real oil price into the common component of core PCE prices. The gray line is the estimated pass-through in the benchmark model (the shaded area is the $90 \%$ confidence band), while the thick black line is the pass-through estimated using the enlarged VAR model described in Appendix A.3 (the thin black lines are the $90 \%$ confidence bands). The right plot compares the estimated pass-through of an unexpected $10 \%$ increase of the real oil price into the common component of core PCE prices with the one estimated into core prices, i.e., ignoring the factor structure. The gray line is the pass-through estimated by fitting a four-variable VAR described in Appendix A.3 (the shaded area is the $90 \%$ confidence band). The thick black line is the pass-through estimated using the enlarged VAR model described in Appendix A.3 (the thin black lines are the $90 \%$ confidence bands). Finally, note that the black lines in the left and the right plot are identical, but the scale of the two plots is different.

The results in Figure A3 contrast with those in Clark and Terry (2010). Clark and Terry (2010), who estimate a time varying parameter VAR including core price inflation, energy price inflation, the unemployment rate, and the Fed funds rate, conclude that starting from 1985 the passthrough from energy price inflation to core price inflation is essentially zero. We reach a different conclusions compared to Clark and Terry (2010) because we include $\chi_{t}^{c}$ in lieu of $\pi_{t}^{c}$ in the VAR model, that is we filter out the more noisy idiosyncratic component thus not letting it affect our estimation. To corroborate this conclusion, in the right plot in Figure A3 we compare the oil price pass-through into core inflation estimated with the larger VAR either including the common factor (black line) or including core PCE inflation (gray line). In other words, the black line filters out the idiosyncratic component, whereas the gray line includes the idiosyncratic component. As we can see, when we do not filter out the idiosyncratic component, the estimated pass-through is not statistically different from zero. This result further confirms the importance of disentangling between common and idiosyncratic movement in price fluctuations.

\section{A.4 Model identification}

As we explain in Section 3.3, in our framework an oil price shock is an unpredicted and unpredictable change in the oil price, and as such it has no "structural interpretation", that is we do not disentangle oil supply shocks from oil demand shocks. In Figure A4 we show results when we estimate the model using the identification scheme proposed by Kilian (2009b), which disentangles between oil supply shock, oil demand shock, and global demand shock. As we can see, the results shown in the main text resemble those of an oil demand shock (bottom row). 
Figure A4: Model identification: Kilian (2009)
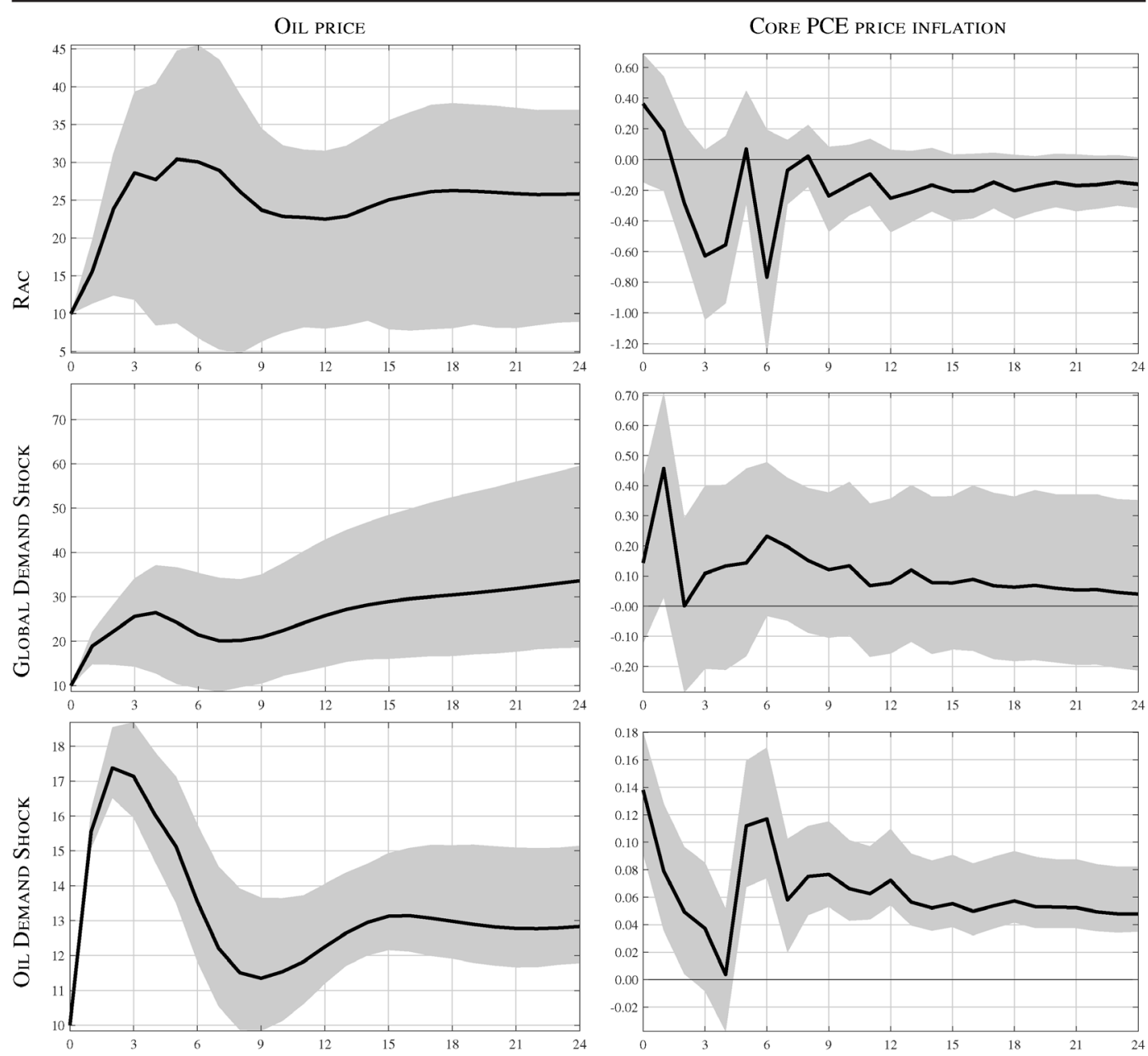

Notes: This figure shows results obtained by using the identification scheme of Kilian (2009) together with $50 \%$ bootstrap confidence bands. In practice we have estimated the same VAR suggested by Kilian (2009) to which we added as fourth variable $\chi_{t}^{\text {core }}$ (ordered last). The left plots show the impulse response function of the real oil price (in levels), while the right plots show the impulse responses of the common component of core inflation. The $x$-axis represents months, while the $y$-axis represents percentage points.

\section{A.5 Oil price indicators}

In the main text, the oil price is measured by Refiners' Acquisition Cost of Crude Oil (RAC) as in, for example, Kilian and Vigfusson (2017). However, as we explained in Section 3.1, an alternative would have been to use the West Texas Intermediate (WTI) spot crude oil price. However, as argued by Kilian (2016), retail gasoline prices depend on the Brent price, so the fact that refineries pay the lower WTI is irrelevant. Brent prices, however, are available only starting in 1987, and therefore we cannot use them in our benchmark sample which starts in 1984.

In Figure A5 we show the estimated pass-through into the common and the idiosyncratic component of core PCE, as well as the historical decomposition, when either Brent or WTI are used instead of RAC. As we can clearly see the results are nearly identical to those shown in the main text. 
Figure A5: Oil price indicators
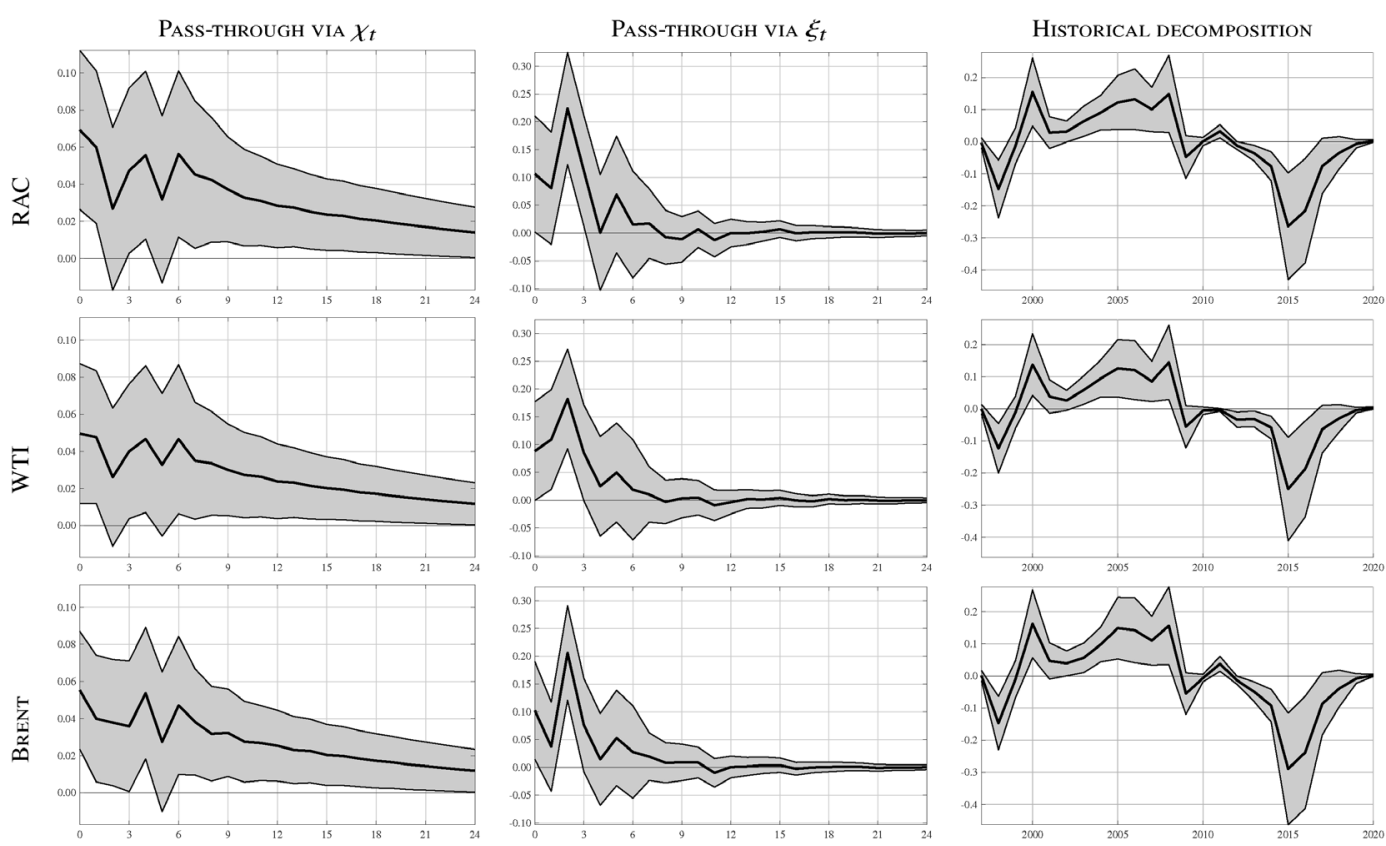

Notes: results in the first raw are obtained by using the Refinery Acquisition Cost as oil price indicator (benchmark results). Results in the second raw are obtained by using WTI as oil price indicator. Results in the third raw are obtained by using Brent as oil price indicator. The model is estimated over the 1996-2016 sample.

\section{APPENDIX 2. DATA}

\section{B.1 The U.S. dataset}

The price data for the U.S. are monthly price indexes for personal consumption expenditures (PCE) by type of product. The data are taken from the NIPA Table 2.4.4U from the Bureau of Economic Analysis and downloaded from Haver. The data were seasonally adjusted by the Bureau of Economic Analysis, and large outliers $-\pi_{i t}$ is considered an outlier if its absolute value is larger than 10 times the interquantile range-were replaced by centered 9-month medians. In the table below the column "ID" reports the position in the NIPA Table 2.4.4U, the column "share" reports the share of variance explained by the common component, while the column "weight" reports the weight of each component in the Total PCE index. The weights are those as of June 2016.

ID Name

\begin{tabular}{lcc} 
Label & share & weight \\
\hline DNMVRX & 4.4 & 2.1 \\
DNPVRX & 0.0 & 1.0 \\
DMVPRX & 0.3 & 0.5 \\
DFFFRX & 8.3 & 1.5 \\
DAPPRX & 2.3 & 0.4 \\
DUTERX & 4.6 & 0.4 \\
DTOORX & 0.0 & 0.2 \\
DVAPRX & 13.9 & 1.8 \\
DSPGRX & 6.2 & 0.6 \\
DWHLRX & 1.7 & 0.4 \\
DRBKRX & 5.3 & 0.3 \\
DMSCRX & 2.5 & 0.1
\end{tabular}




\begin{tabular}{|c|c|c|c|c|}
\hline ID & Name & Label & share & weight \\
\hline 61 & Jewelry and watches & DJRYRX & 2.0 & 0.6 \\
\hline 64 & Therapeutic appliances and equipment & DTAERX & 12.2 & 0.6 \\
\hline 67 & Educational books & DEBKRX & 2.8 & 0.1 \\
\hline 68 & Luggage and similar personal items & DLUGRX & 2.8 & 0.3 \\
\hline 69 & Telephone and facsimile equipment & DTCERX & 20.1 & 0.1 \\
\hline 74 & Cereals and bakery products & DCBPRX & 12.8 & 1.1 \\
\hline 77 & Meats and poultry & DMAPRX & 0.8 & 1.2 \\
\hline 82 & Fish and seafood & DFISRX & 0.9 & 0.1 \\
\hline 83 & Milk, dairy products, and eggs & DMDERX & 1.2 & 0.6 \\
\hline 87 & Fats and oils & DFATRX & 1.9 & 0.1 \\
\hline 88 & Fresh fruits and vegetables & DFAVRX & 0.5 & 0.7 \\
\hline 91 & Processed fruits and vegetables & DPFVRX & 2.7 & 0.2 \\
\hline 92 & Sugar and sweets & DSWERX & 2.4 & 0.4 \\
\hline 93 & Food products, not elsewhere classified & DOFDRX & 6.7 & 1.1 \\
\hline 94 & Nonalcoholic beverages purchased for off-premises consumption & DNBVRX & 1.0 & 0.7 \\
\hline 97 & Alcoholic beverages purchased for off-premises consumption & DAOPRX & 6.9 & 1.1 \\
\hline 101 & Food produced and consumed on farms & DFFDRX & 0.1 & 0.0 \\
\hline 103 & Garments & DGARRX & 3.2 & 2.4 \\
\hline 107 & Other clothing materials and footwear & DOCCRX & 2.3 & 0.7 \\
\hline 112 & Motor vehicle fuels, lubricants, and fluids & DMFLRX & 0.3 & 2.0 \\
\hline 115 & Fuel oil and other fuels & DFULRX & 0.6 & 0.2 \\
\hline 119 & Pharmaceutical and other medical products & DPHMRX & 15.2 & 3.8 \\
\hline 124 & Recreational items & DREIRX & 11.6 & 1.3 \\
\hline 129 & Household supplies & DHOURX & 6.9 & 1.0 \\
\hline 135 & Personal care products & DOPCRX & 2.9 & 1.0 \\
\hline 139 & Tobacco & DTOBRX & 3.0 & 0.8 \\
\hline 140 & Magazines, newspapers, and stationery & DNEWRX & 3.8 & 0.8 \\
\hline 152 & Rental of tenant-occupied nonfarm housing & DTENRX & 30.7 & 4.0 \\
\hline 156 & Imputed rental of owner-occupied nonfarm housing & DOWNRX & 26.1 & 11.5 \\
\hline 160 & Rental value of farm dwellings & DFARRX & 1.4 & 0.2 \\
\hline 163 & Group housing & DGRHRX & 28.8 & 0.0 \\
\hline 164 & Water supply and sewage maintenance & DWSMRX & 1.4 & 0.6 \\
\hline 166 & Garbage and trash collection & DREFRX & 37.2 & 0.1 \\
\hline 167 & Electricity & DELCRX & 1.7 & 1.4 \\
\hline 167 & Natural gas & DGHERX & 0.5 & 0.4 \\
\hline 170 & Physician services & DPHYRX & 30.9 & 4.0 \\
\hline 171 & Dental services & DDENRX & 29.2 & 1.0 \\
\hline 172 & Paramedical services & DPMSRX & 22.5 & 2.7 \\
\hline 179 & Hospitals & DHSPRX & 44.9 & 8.0 \\
\hline 183 & Nursing homes & DNRSRX & 5.5 & 1.4 \\
\hline 187 & Motor vehicle services & DMVSRX & 12.5 & 2.1 \\
\hline 196 & Ground transportation & DGRDRX & 1.5 & 0.4 \\
\hline 203 & Air transportation & DAITRX & 0.4 & 0.4 \\
\hline 204 & Water transportation & DWATRX & 1.2 & 0.0 \\
\hline 206 & Membership clubs, sports centers, parks, theaters, and museums & DRLSRX & 6.5 & 1.5 \\
\hline 204 & Audio-video, photographic, and information processing equipment services & DAVPRX & 6.0 & 0.8 \\
\hline 220 & Gambling & DGAMRX & 12.9 & 1.0 \\
\hline 224 & Other recreational services & DOTRRX & 7.3 & 0.5 \\
\hline 231 & Meals and nonalcoholic beverages & DMABRX & 24.2 & 4.8 \\
\hline 239 & Alcohol in purchased meals & DAPMRX & 13.1 & 0.7 \\
\hline 240 & Food furnished to employees (including military) & DFOORX & 2.7 & 0.2 \\
\hline 243 & Accommodations & DACCRX & 1.6 & 1.0 \\
\hline 248 & Financial services furnished without payment & DIMPRX & 5.0 & 2.6 \\
\hline 252 & Financial service charges, fees, and commissions & DOFIRX & 0.5 & 2.0 \\
\hline 265 & Life insurance & DLIFRX & 13.3 & 0.7 \\
\hline 266 & Net household insurance & DFINRX & 0.1 & 0.1 \\
\hline 269 & Net health insurance & DHINRX & 3.9 & 1.5 \\
\hline 273 & Net motor vehicle and other transportation insurance & DTINRX & 0.0 & 0.5 \\
\hline 275 & Communication & DCORMG & 3.3 & 2.2 \\
\hline 285 & Higher education & DHEDRX & 18.8 & 1.5 \\
\hline 288 & Nursery, elementary, and secondary schools & DNEHRX & 23.1 & 0.3 \\
\hline
\end{tabular}




\begin{tabular}{|c|c|c|c|c|}
\hline ID & Name & Label & share & weight \\
\hline 291 & Commercial and vocational schools & DVEDRX & 0.0 & 0.4 \\
\hline 293 & Legal services & DGALRX & 11.6 & 0.8 \\
\hline 294 & Accounting and other business services & DPRORX & 2.0 & 0.3 \\
\hline 298 & Labor organization dues & DUNSRX & 3.0 & 0.1 \\
\hline 299 & Professional association dues & DAXSRX & 11.6 & 0.1 \\
\hline 300 & Funeral and burial services & DFUNRX & 16.5 & 0.2 \\
\hline 302 & Personal care services & DPCSRX & 12.4 & 1.1 \\
\hline 305 & Clothing and footwear services & DCFSRX & 12.4 & 0.1 \\
\hline 310 & Child care & DCHCRX & 0.9 & 0.3 \\
\hline 311 & Social assistance & DSCWRX & 8.4 & 0.9 \\
\hline 318 & Social advocacy and civic and social organizations & DSADRX & 5.5 & 0.1 \\
\hline 319 & Religious organizations' services to households & DRELRX & 0.5 & 0.1 \\
\hline 320 & Foundations and grantmaking and giving services to households & DGIVRX & 1.5 & 0.0 \\
\hline 321 & Household maintenance & DHHMRX & 3.1 & 0.6 \\
\hline 339 & Final consumption expenditures of NPISH & DNPIRX & 8.3 & 2.7 \\
\hline
\end{tabular}

\section{B.2 The euro area dataset}

The price data for the euro area are monthly price indexes for Harmonized Indexes of Consumer Prices (HICP) by type of product taken from the Eurostat website http://appsso.eurostat. ec.europa.eu/nui/show.do?dataset=prc_hicp_midx lang=en. The data were seasonally adjusted by using the X-12-ARIMA seasonal adjustment method, and large outliers $-\pi_{i t}$ is considered an outlier if its absolute value is larger than 10 times the interquantile range-were replaced by centered 9-month medians. In the table below the column "share" reports the share of variance explained by the common component, while the column "weight" reports the weight of each component in the Total HICP index. The weights are those as of 2016.

\begin{tabular}{lccc} 
Name & Label & share & weight \\
\hline Bread and cereals & CP0111 & 48.9 & 2.8 \\
Meat & CP0112 & 23.6 & 3.7 \\
Fish and seafood & CP0113 & 1.5 & 1.1 \\
Milk, cheese and eggs & CP0114 & 27.8 & 2.2 \\
Oils and fats & CP0115 & 2.3 & 0.5 \\
Fruit & CP0116 & 2.6 & 1.3 \\
Vegetables & CP0117 & 1.0 & 1.8 \\
Sugar, jam, honey, chocolate and confectionery & CP0118 & 33.5 & 1.0 \\
Food products n.e.c. & CP0119 & 36.9 & 0.6 \\
Coffee, tea and cocoa & CP0121 & 0.9 & 0.5 \\
Mineral waters, soft drinks, fruit and vegetable juices & CP0122 & 33.5 & 1.0 \\
Spirits & CP0211 & 7.2 & 0.4 \\
Wine & CP0212 & 10.7 & 0.8 \\
Beer & CP0213 & 6.8 & 0.6 \\
Tobacco & CP022 & 1.2 & 2.5 \\
Clothing materials & CP0311 & 0.2 & 0.0 \\
Garments & CP0312 & 2.8 & 4.7 \\
Other articles of clothing and clothing accessories & CP0313 & 1.1 & 0.3 \\
Cleaning, repair and hire of clothing & CP0314 & 16.0 & 0.2 \\
Shoes and other footwear & CP0321-322 & 1.9 & 1.3 \\
Actual rentals paid by tenants & CP0411-412 & 2.0 & 6.8 \\
Materials for the maintenance and repair of the dwelling & CP0431 & 21.8 & 0.4 \\
Services for the maintenance and repair of the dwelling & CP0432 & 27.5 & 0.9 \\
Water supply & CP0441 & 0.1 & 0.7 \\
Refuse collection & CP0442 & 0.0 & 0.6 \\
Sewerage collection & CP0443 & 0.0 & 0.6 \\
Other services relating to the dwelling n.e.c. & CP0444 & 0.5 & 1.0 \\
Electricity & CP0451 & 8.7 & 2.9
\end{tabular}




\begin{tabular}{|c|c|c|c|}
\hline Name & Label & share & weight \\
\hline Gas & CP0452 & 11.8 & 2.0 \\
\hline Liquid fuels & CP0453 & 0.0 & 0.7 \\
\hline Solid fuels & CP0454 & 10.0 & 0.2 \\
\hline Heat energy & CP0455 & 14.2 & 0.2 \\
\hline Furniture and furnishings & CP0511 & 29.3 & 2.0 \\
\hline Carpets and other floor coverings & CP0512 & 2.1 & 0.2 \\
\hline Repair of furniture, furnishings and floor coverings & CP0513 & 11.0 & 0.1 \\
\hline Household textiles & $\mathrm{CP} 0520$ & 5.3 & 0.5 \\
\hline Major household appliances whether electric or not & СР0531-532 & 5.8 & 0.9 \\
\hline Repair of household appliances & CP0533 & 5.4 & 0.1 \\
\hline Glassware, tableware and household utensils & CP0540 & 12.6 & 0.5 \\
\hline Major tools and equip. and small tools and misc. accessories & СР0551-552 & 21.0 & 0.5 \\
\hline Non-durable household goods & CP0561 & 36.8 & 1.0 \\
\hline Domestic services and household services & CP0562 & 5.1 & 1.0 \\
\hline Pharmaceutical products & CP0611 & 0.6 & 1.3 \\
\hline Other medical products, therapeutic appliances and equipment & СР0612-613 & 4.9 & 0.8 \\
\hline Motor cars & $\mathrm{CP} 0711$ & 0.1 & 3.7 \\
\hline Motor cycles, bicycles and animal drawn vehicles & СР0712-714 & 0.1 & 0.3 \\
\hline Spare parts and accessories for personal transport equipment & $\mathrm{CP} 0721$ & 19.4 & 0.6 \\
\hline Fuels and lubricants for personal transport equipment & CP0722 & 0.0 & 4.4 \\
\hline Maintenance and repair of personal transport equipment & CP0723 & 42.6 & 2.6 \\
\hline Other services in respect of personal transport equipment & $\mathrm{CP} 0724$ & 13.0 & 1.3 \\
\hline Passenger transport by railway & CP0731 & 2.3 & 0.7 \\
\hline Passenger transport by road & $\mathrm{CP} 0732$ & 3.7 & 0.6 \\
\hline Passenger transport by air & CP0733 & 0.2 & 0.7 \\
\hline Passenger transport by sea and inland waterway & $\mathrm{CP} 0734$ & 0.5 & 0.1 \\
\hline Combined passenger transport & CP0735 & 1.4 & 0.6 \\
\hline Other purchased transport services & CP0736 & 5.8 & 0.1 \\
\hline Postal services & CP081 & 3.0 & 0.2 \\
\hline Telephone and telefax equipment & СР0820-830 & 0.0 & 3.1 \\
\hline Equipment for the reception, recording and reproduction of sound and picture & CP0911 & 7.0 & 0.5 \\
\hline Photographic and cinematographic equipment and optical instruments & CP0912 & 14.5 & 0.1 \\
\hline Information processing equipment & CP0913 & 17.1 & 0.5 \\
\hline Recording media & СР0914 & 0.0 & 0.2 \\
\hline Repair of audio-visual, photographic and information processing equipment & CP0915 & 2.7 & 0.1 \\
\hline Major durables for outdoor recreation and indoor recreation & CP0921-922 & 1.4 & 0.3 \\
\hline Maintenance and repair of other major durables for recreation and culture & СР0923 & 2.7 & 0.0 \\
\hline Games, toys and hobbies & CP0931 & 0.7 & 0.6 \\
\hline Equipment for sport, camping and open-air recreation & CP0932 & 3.6 & 0.3 \\
\hline Gardens, plants and flowers & CP0933 & 0.4 & 0.6 \\
\hline Pets and related products; veterinary and other services for pets & CP0934-935 & 37.7 & 0.7 \\
\hline Recreational and sporting services & СР0941 & 2.9 & 1.0 \\
\hline Cultural services & CP0942 & 4.8 & 1.5 \\
\hline Books & CP0951 & 0.2 & 0.6 \\
\hline Newspapers and periodicals & CP0952 & 0.7 & 0.7 \\
\hline Miscellaneous printed matter;stationery and drawing materials & СР0953-954 & 12.6 & 0.4 \\
\hline Package holidays & СР096 & 0.0 & 1.8 \\
\hline Pre-primary, primary, second., etc, and educ. not def. by level & CP10X0 & 4.7 & 1.1 \\
\hline Restaurants, cafés and the like & CP1111 & 44.1 & 7.5 \\
\hline Canteens & CP1112 & 8.0 & 0.7 \\
\hline Accommodation services & CP112 & 0.0 & 1.9 \\
\hline Hairdressing salons and personal grooming establishments & CP1211 & 19.4 & 1.3 \\
\hline $\begin{array}{l}\text { Electrical appliances for personal care; other appliances, articles and products } \\
\text { for personal care }\end{array}$ & CP1212-1213 & 40.4 & 1.8 \\
\hline Jewelery, clocks and watches & CP1231 & 15.1 & 0.5 \\
\hline Other personal effects & CP1232 & 5.5 & 0.5 \\
\hline Insurance connected with the dwelling & $\mathrm{CP} 1252$ & 1.1 & 0.3 \\
\hline Insurance connected with transport & $\mathrm{CP} 1254$ & 1.4 & 0.9 \\
\hline Other financial services n.e.c. & CP12622 & 0.1 & 0.6 \\
\hline Other services n.e.c. & CP127 & 10.5 & 1.1 \\
\hline
\end{tabular}




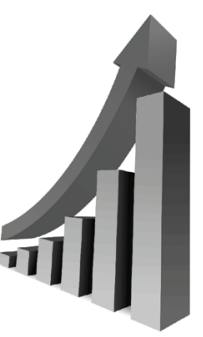

\section{T A C A Association for WWW.IAEE.ORG

The IAEE is pleased to announce that our leading publications exhibited strong performances in the latest 2018 Impact Factors as reported by Clarivate. The Energy Journal achieved an Impact Factor of 2.456 while Economics of Energy \& Environmental Policy saw an increase to 2.034.

Both publications have earned SCIMago Journal Ratings in the top quartile for Economics and Econometrics publications.

IAEE wishes to congratulate and thank all those involved including authors, editors, peer-reviewers, the editorial boards of both publications, and to you, our readers and researchers, for your invaluable contributions in making 2018 a strong year. We count on your continued support and future submission of papers to these leading publications. 